Article

\title{
Numerical and Experimental Investigations on Reducing Particle Accumulation for SCR-deNO Facilities
}

\author{
Haojun Zeng ${ }^{1,2} \mathbb{C}^{-}$, Jingqi Yuan ${ }^{1,2, *}$ and Jingcheng Wang ${ }^{1,2}$ \\ 1 Department of Automation, Shanghai Jiao Tong University, 800 Dongchuan Road, Shanghai 200240, China; \\ tsang000@sjtu.edu.cn (H.Z.); jcwang@sjtu.edu.cn (J.W.) \\ 2 The Key Laboratory of System Control and Information Processing, Ministry of Education of China, \\ 800 Dongchuan Road, Shanghai 200240, China \\ * Correspondence: jqyuan@sjtu.edu.cn; Tel.: +86-(0)21-3420-4055
}

Received: 12 September 2019; Accepted: 30 September 2019; Published: 3 October 2019

\begin{abstract}
Selective catalytic reduction (SCR) is widely used to remove nitrogen oxides $\left(\mathrm{NO}_{x}\right)$ in the flue gas of coal-fired power plants. The accumulation of ash particles inside the SCR-deNO $x$ facility will increase the risk of catalyst deactivation or even damage. This paper presents the numerical and experimental investigations on the particle dispersal approach for the SCR-deNO $x$ facility of a $1000 \mathrm{MW}$ coal-fired power plant. The accumulation of different-sized particles is evaluated based on computational fluid dynamics (CFD) simulations. To prevent particles from accumulation, an optimized triangular deflector is proposed and attempts are made to find out the optimal installing position of the deflector. For the $\pi$-type SCR-deNO ${ }_{x}$ facilities, the particle accumulation predominantly occurred on one side of the catalysts' entrance, which corresponds to the inner side of the wedge-shaped turning. It is indicated that particles larger than $8.8 \times 10^{-2} \mathrm{~mm}$ are responsible for the significant accumulation. The triangular deflector is proved to be an effective way to reduce particle accumulation and is found most efficient when it is installed at the high-speed area of the vertical duct. Flow model test (FMT) is carried out to validate the dispersal effect for the particle with relatively large sizes and the optimal installing position of the triangular deflector.
\end{abstract}

Keywords: selective catalytic reduction (SCR); particle accumulation; computational fluid dynamics (CFD); flow model test (FMT); particle dispersal approach

\section{Introduction}

Coal-fired power plants are the major contributors to the emission of nitrogen oxides $\left(\mathrm{NO}_{x}\right) \cdot \mathrm{NO}_{x}$ is not only responsible for the formation of acid rain and ozone layer weakening but also the potential inducement for respiratory diseases of human beings [1,2]. According to the Emissions Database for Global Atmospheric Research (EDGAR) released by the European Commission, in the past 40 years, global emissions of $\mathrm{NO}_{x}$ increased from 68 to 122 megatons [3,4]. In Europe, energy production and distribution accounts for $19.48 \%$ of the total $\mathrm{NO}_{x}$ emission. For new, large gas- and coal-fired power plants, the $\mathrm{NO}_{x}$ emission limits are set to be $50-100 \mathrm{mg} / \mathrm{Nm}^{3}$ and $150-200 \mathrm{mg} / \mathrm{Nm}^{3}$, respectively [4-7]. In 2015, the $\mathrm{NO}_{x}$ emission in China was 18.52 megatons [8,9]. Following the ultra-low emission standard of China, the $\mathrm{NO}_{x}$ emission limit should not exceed $50 \mathrm{mg} / \mathrm{m}^{3}$ for newly built coal-fired power plants $[10,11]$. To meet the more stringent regulations on $\mathrm{NO}_{x}$ emission, selective catalytic reduction (SCR) is widely applied due to its high efficiency, economics and mature technology $[12,13]$.

In the coal-fired power plant, the SCR facility is usually installed between the boiler and the air preheater [13-16] and works with the dust-laden gas. The accumulation and the deposition of the ash particles, especially the large-sized particles, will increase the risk of catalyst deactivation $[17,18]$. 
Although soot blowers are used before the catalyst layers $[13,19,20]$, the blockage and erosion of the monolith catalysts often occur. Figure 1a shows the breakage of the catalyst layer for a $660 \mathrm{MW}$ coal-fired power plant. Moreover, the high-speed flue gas containing ash particles would lead to severe erosion on the ammonia injection grid (AIG) and the support structure, as shown in Figure 1b. It would shorten the lifetime of the catalysts and threaten the performance of the SCR-deNO facility. $^{2}$ Hence, it is necessary to investigate the distribution of ash particles and take steps to disperse particle accumulation inside the $\mathrm{SCR}-\mathrm{deNO}_{x}$ facility.

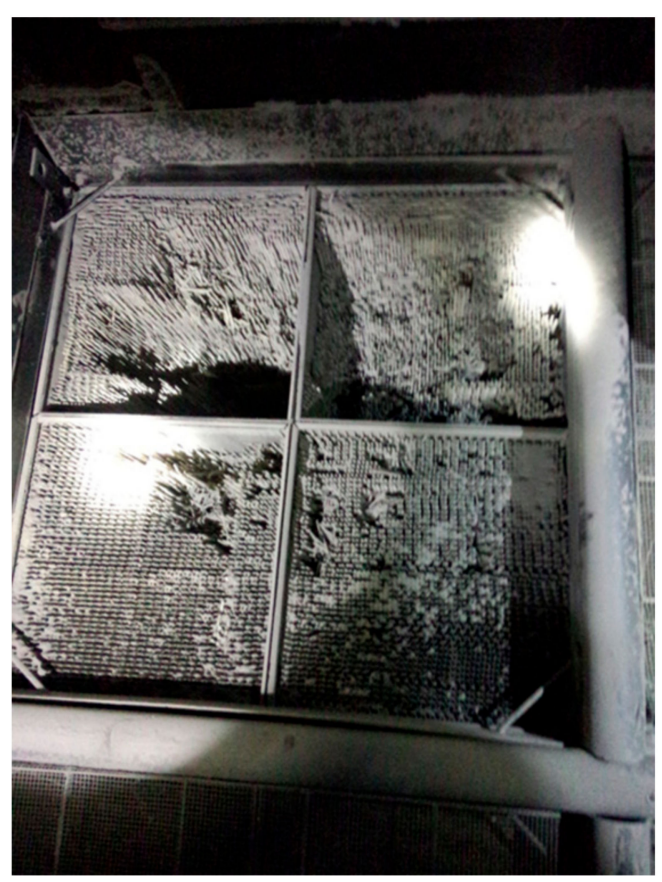

(a)

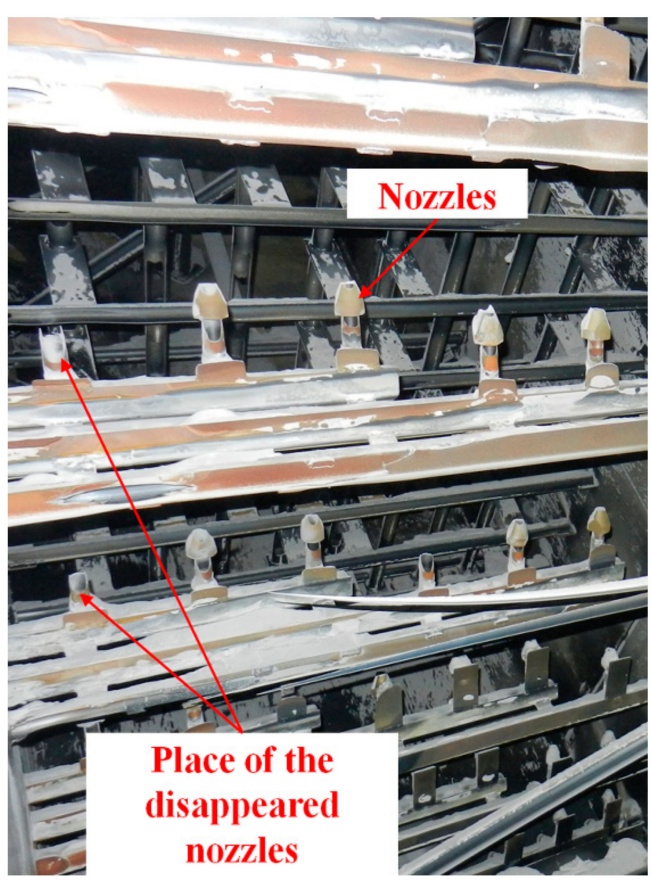

(b)

Figure 1. The damage caused by ash particles: (a) the breakage of the catalyst layer for a $660 \mathrm{MW}$ coal-fired power plant, (b) the erosion of the ammonia injection grid (AIG) and the support structure.

Recently, with the assistance of computational fluid dynamics (CFD), studies have been made

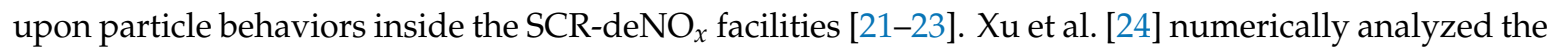
catalyst breakage failure and presented the particle distributions at the entrance of the catalyst layers under different baffles configurations. Yu et al. [25] experimentally and numerically studied the catalyst erosion of the SCR-deNO $x$ reactor for a $660 \mathrm{MW}$ coal-fired power plant. An integrated approach was proposed to predict the erosion condition and implement erosion optimization. Feng et al. [26] presented a detailed investigation of particle deposition in monolith SCR-deNO $\mathrm{N}_{x}$ catalysts. The effects of particle diameter, particle density, gas velocity, turbulent intensity, chemical reaction and channel size were studied. Pilot-scale experiments on particle deposition of SCR-deNO ${ }_{x}$ catalysts were carried out by Heiredal et al. [27] and a model was developed, revealing the dominating mechanisms for particle deposition. Nevertheless, few research papers focus on the particle accumulation inside the duct and the corresponding solutions.

In the present study, CFD simulations are carried out for the SCR-deNO ${ }_{x}$ facility of a $1000 \mathrm{MW}$ coal-fired power plant. Particle accumulation inside the duct is investigated with different particle sizes. A triangular deflector is proposed to disperse the particles with relatively large sizes and reduce accumulation. Optimal design is implemented on the structural parameters of the triangular deflector, including the angle against the wind and the height. Furthermore, the installing position of the triangular deflector in the vertical duct is assessed and optimized. The corresponding flow model test (FMT) is conducted with the optimized deflector as a validation of the dispersal effect and the optimal 
installing position. The installation of the triangular deflector is proven to be an efficient approach to

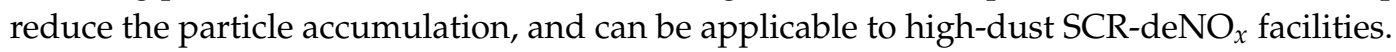

\section{Computational Fluid Dynamics (CFD) Simulations and Flow Model Test (FMT) Experiments}

\subsection{Description of the $\mathrm{SCR}-\mathrm{deNO} \mathrm{N}_{x}$ Facility}

The schematic geometry of the SCR-deNO ${ }_{x}$ facility for a $1000 \mathrm{MW}$ coal-fired power plant is shown in Figure 2. This power plant is built by Guangdong Baolihua New Energy Stock Co., Ltd. and is located in Hudong Town, Lufeng City, Guangdong Province of China ( $22^{\circ} 49^{\prime} 56^{\prime \prime} \mathrm{N}, 115^{\circ} 59^{\prime} 10^{\prime \prime}$ E). The baffles geometry is optimized to regulate the flow field and obtain a homogeneous distribution of gas velocity at the entrance of the catalysts.

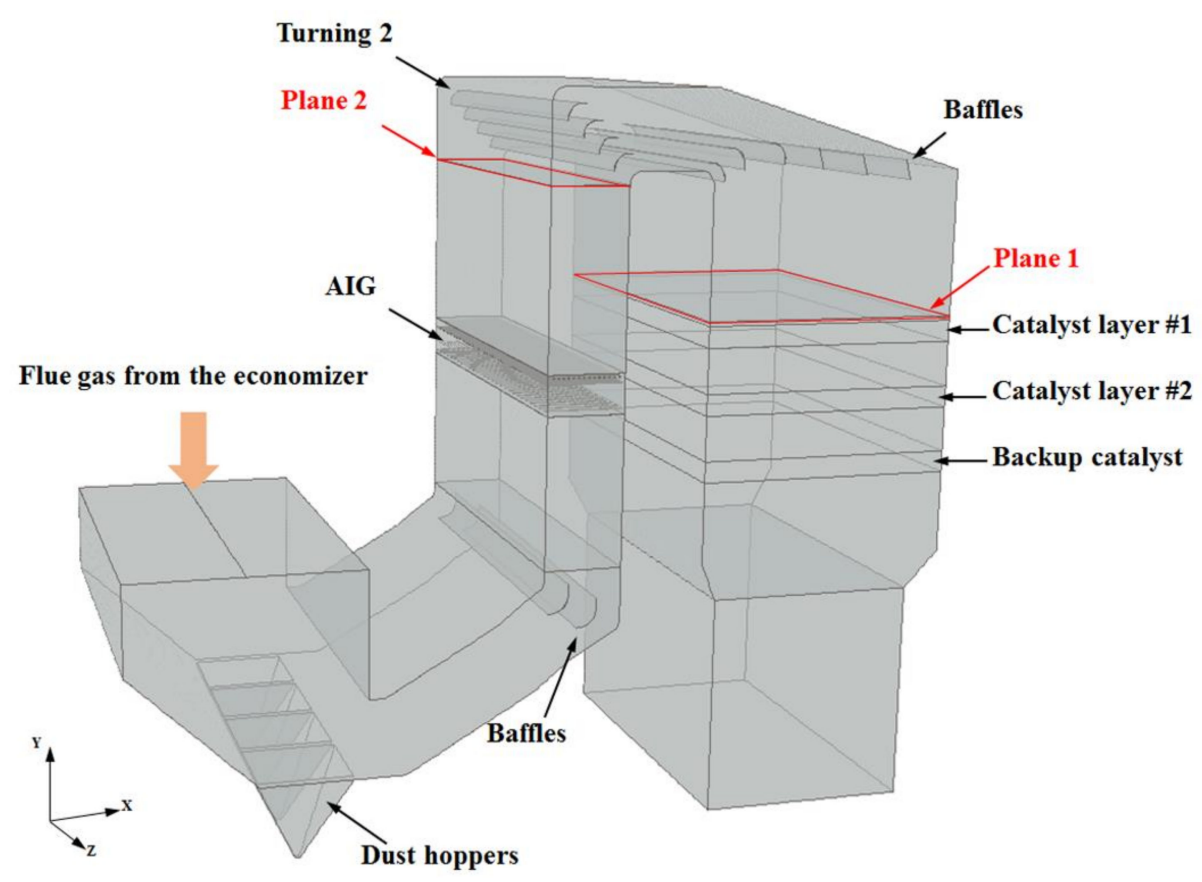

Figure 2. The schematic geometry of the $\mathrm{SCR}-\mathrm{deNO}_{x}$ facility for a $1000 \mathrm{MW}$ coal-fired power plant.

The SCR-deNO ${ }_{x}$ facility shown in Figure 2 is the classic $\pi$ type. The height of the facility is about $33,000 \mathrm{~mm}$ while the inlet size is about $10,000 \mathrm{~mm} \times 19,000 \mathrm{~mm}$. The sectional area of the catalyst layer is about $194 \mathrm{~m}^{2}$. The flue gas leaving the economizer passes the dust hoppers and enters the sloped duct. Then, it goes through the AIG and hybrid grid in the vertical duct. After passing the wedge-shaped turning and the straightener, it finally enters the two catalyst layers. At the $100 \%$ boiler maximum continuous rating (BMCR) operational condition, the total flow rate of the flue gas is $979.60 \mathrm{~kg} / \mathrm{s}$ with a temperature of $648 \mathrm{~K}$. The mass flow rate of the ash particles is $12.54 \mathrm{~kg} / \mathrm{s}$. The characteristics of the ash particles including the diameter distribution are presented by the Instrumental Analysis Center of Shanghai Jiao Tong University, which is shown in Table 1.

Table 1. The characteristics of the ash particles collected from the SCR-deNO $\mathrm{S}_{x}$ facility.

\begin{tabular}{ccc}
\hline Density & Particle Diameter $\boldsymbol{\Phi}$ & Mass Fraction \\
\hline & $>0.15 \mathrm{~mm}$ & $10.97 \%$ \\
$1.0 \mathrm{~g} / \mathrm{cm}^{3}$ & $8.8 \times 10^{-2} \mathrm{~mm}<\boldsymbol{\Phi} \leq 0.15 \mathrm{~mm}$ & $8.07 \%$ \\
& $6.3 \times 10^{-2} \mathrm{~mm}<\boldsymbol{\Phi} \leq 8.8 \times 10^{-2} \mathrm{~mm}$ & $2.92 \%$ \\
& $\leq 6.3 \times 10^{-2} \mathrm{~mm}$ & $78.04 \%$ \\
\hline
\end{tabular}




\subsection{Computational Fluid Dynamics (CFD) Simulations}

CFD simulations are carried out by ANSYS Fluent 17.1 [28]. On the basis of grid convergence analysis, which is shown in Appendix A, the three-dimensional meshing model is established with the real scale. It ranges from $-5132 \mathrm{~mm}$ to $32,008 \mathrm{~mm}$ in the $X$ direction, from $-11,000 \mathrm{~mm}$ to $22,489 \mathrm{~mm}$ in the $\mathrm{Y}$ direction and from $-10,155 \mathrm{~mm}$ to $9465 \mathrm{~mm}$ in the $\mathrm{Z}$ direction. The total meshing number is about 3.85 million. Hex/Wedge and Tet/Hybrid grids are used to demonstrate the meshing geometry. For simplification, several assumptions are made for the calculation: (1) the model is considered to be adiabatic since the SCR-deNO ${ }_{x}$ facility is covered with an aluminum silicate blanket, which works as the thermal insulator, (2) no chemical reaction is introduced, (3) the gas flow is considered to be incompressible fluid, (4) the ash particles are treated as inert particles, and (5) the diameters for $99.50 \%$ of the ash particles are larger than $2.50 \times 10^{-3} \mathrm{~mm}[25,26,29]$.

Accordingly, the Raynolds Averaged Navier Stokes (RANS) equations are used to handle the turbulence and the standard $\mathrm{k}-\varepsilon$ model is adopted. Meanwhile, the semi-implicit method for pressure-linked equation (SIMPLE) algorithm is chosen to solve the governing equations and second order upwind is used as the discretization scheme. The discrete phase model (DPM), which is under a Lagrange framework, is used to track the particle trajectories. The particles interact with the gas flow and the corresponding diameter distribution follows the Rosin-Rammler rule. According to the data in Table 1, the mean diameter and the spread parameter is calculated to be $3.5 \times 10^{-2} \mathrm{~mm}$ and 0.79 , respectively. Boundary conditions are given as follows: the facility inlet is set to be velocity inlet with the flow rate of $4.50 \mathrm{~m} / \mathrm{s}$ while the facility outlet is set to be pressure outlet. Moreover, the porous zone model is used to represent the catalyst layers with an inertial resistance coefficient of 30.85 .

In the simulation cases, an observation plane named plane 1 is located $200 \mathrm{~mm}$ above the catalyst layer \#1 to represent the velocity distribution and particle distribution at the entrance of the catalyst layers. Another observation plane named plane 2 is located at the entrance of turning 2, representing the particle distribution in the vertical duct.

To study the ash particle accumulation, CFD simulations are carried out with the arrangement shown in Figure 2. The particle distributions of plane 1 and plane 2 are presented subsequently. Based on the flow field, a triangular deflector is presented and installed in the vertical duct, aiming to disperse the accumulated particles and avoid severe impact on the velocity distribution. The sectional view of the triangular deflector is shown in Figure 3. Two sets of simulations are carried out to determine the optimal geometry of the triangular deflector. The first set is to investigate the optimal angle against the wind. The angle is set to be $10^{\circ}, 15^{\circ}, 30^{\circ}, 45^{\circ}, 60^{\circ}$ respectively, with a fixed height of $300 \mathrm{~mm}$. The second set aims to achieve the optimal height of the deflector. The height is set to be $100 \mathrm{~mm}, 200 \mathrm{~mm}, 300 \mathrm{~mm}, 500 \mathrm{~mm}, 700 \mathrm{~mm}$ respectively, while the angle is maintained at $15^{\circ}$. The simulation results are compared and analyzed based on the velocity distribution, total pressure loss and particle accumulation.

Attempts are also made to investigate the optimal installing position for the triangular deflector in the vertical duct. The deflector is installed at three different heights, as shown in Figure 4. The corresponding simulations are carried out with a low deflector installation, a middle deflector installation and a high deflector installation, respectively. Comparisons are made among the simulation results of these cases and data processing is conducted via MATLAB to evaluate the dispersal effect. 


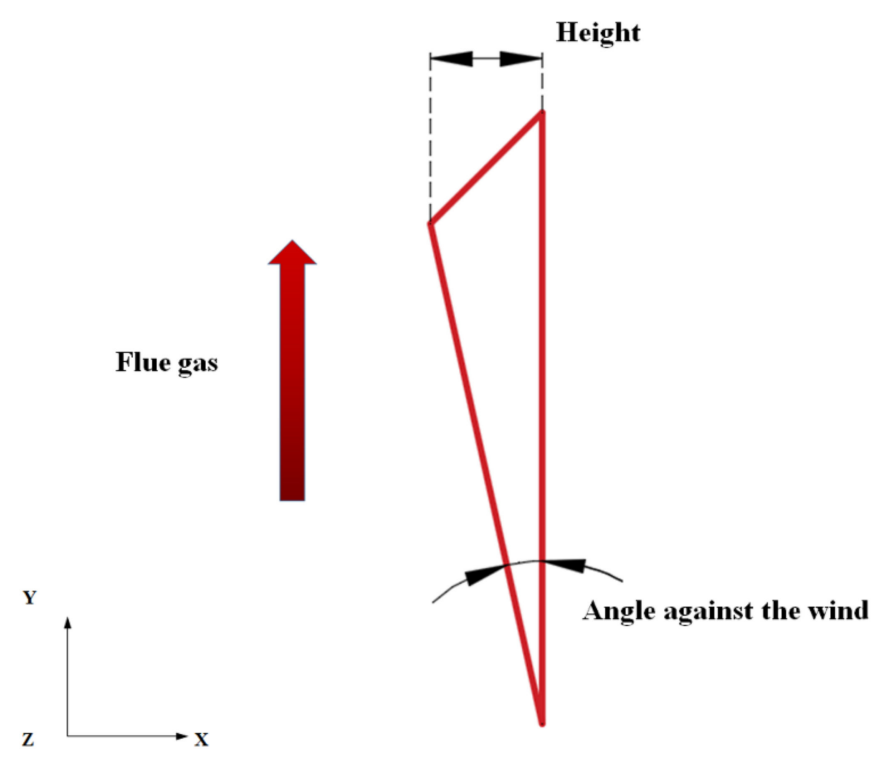

Figure 3. The schematic view of the triangular deflector (Z-positive).

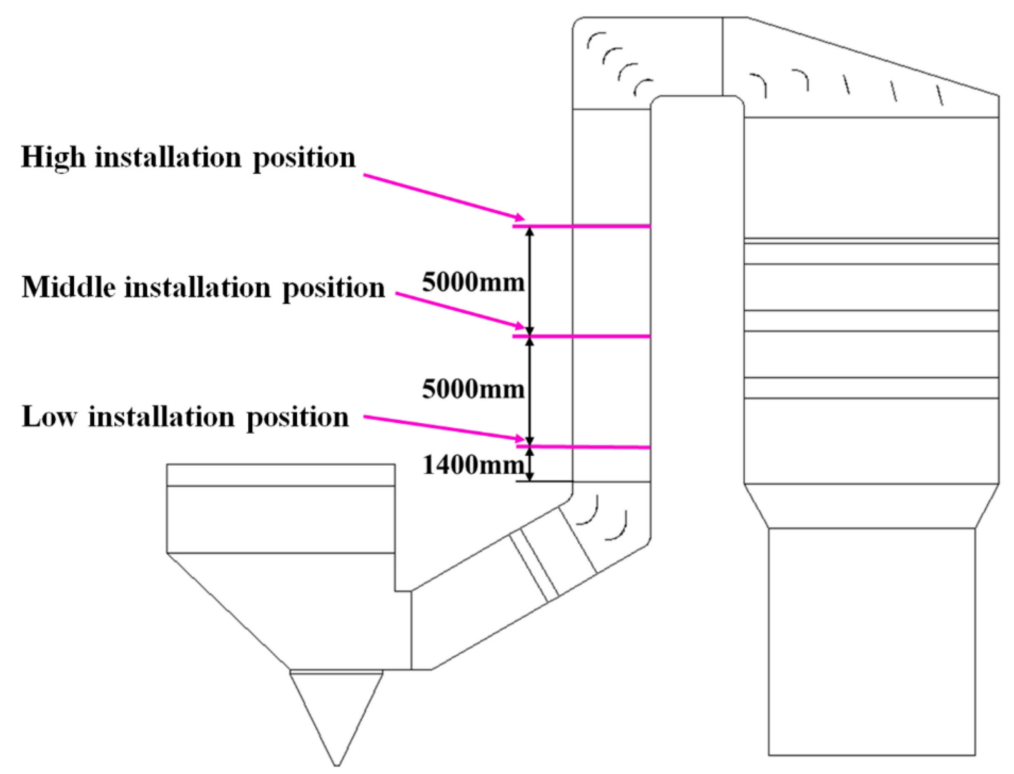

Figure 4. Three different installing positions for the triangular deflector (Z-positive).

\subsection{Flow Model Test (FMT) Experiments}

The flow model test is performed as a validation, focusing on the dispersal effect of the optimized triangular deflector for the accumulated particles with relatively large sizes. The optimal installing position of the triangular deflector is verified. The schematic view of the FMT platform is shown in Figure 5. 


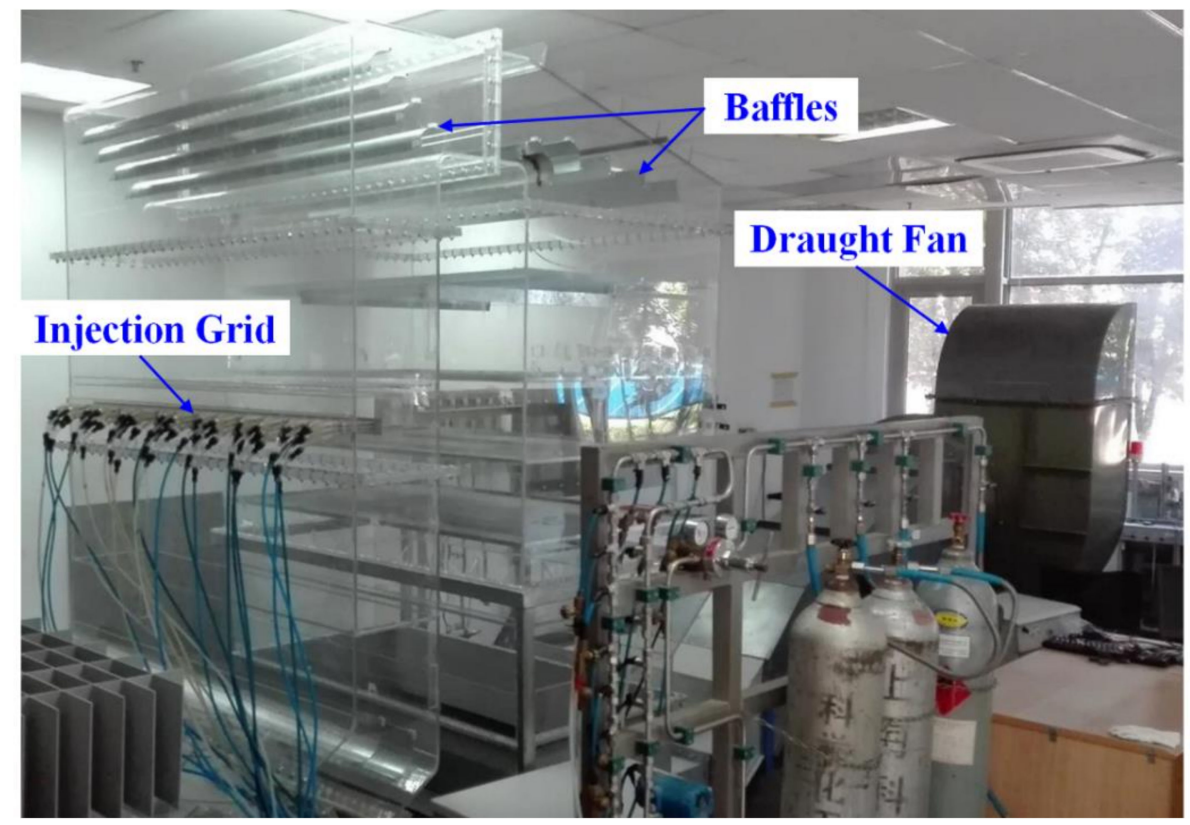

Figure 5. The platform of flow model test (FMT) experiments.

The SCR-deNO $\mathrm{N}_{x}$ facility with a scale of $1: 12$ is made from plexiglas while the baffles geometry is made of aluminum slices. Perforated plates are substituted for the catalyst layers to provide the pressure drop. Several small holes are processed in advance on the plexiglas as follows: six of them are used to set the triangular deflectors, as shown in Figure 6a. Meanwhile, the other nine of them are located above the perforated plates and are used for the measurement, which is shown in Figure $6 \mathrm{~b}$. As can be seen, they are sealed with plastic tapes if no measurement is conducted.

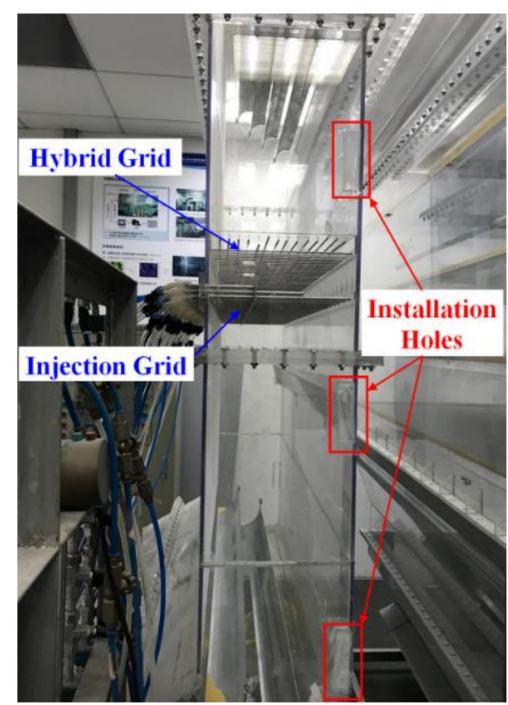

(a)

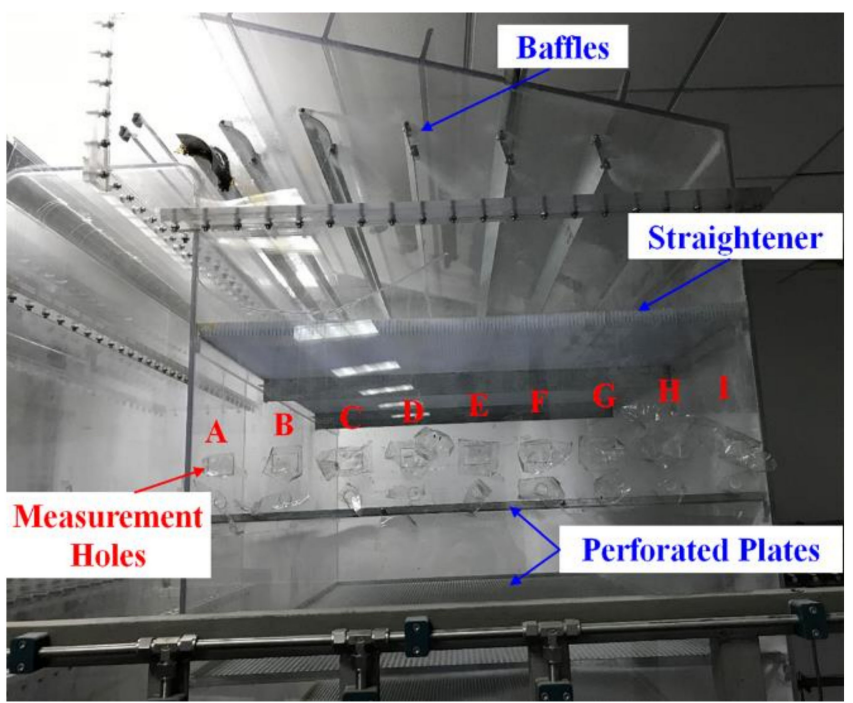

(b)

Figure 6. The small holes processed on the Plexiglas: (a) holes for setting the deflector, (b) holes for measurement (labelled as A-I).

Since chemical reaction is not considered, air is substituted for the flue gas. The air velocity at the inlet is modified to be close to $4.50 \mathrm{~m} / \mathrm{s}$, which is in accordance with the $100 \%$ BMCR condition. To avoid environmental pollution, crushed millet is used to substitute for the ash particles with relatively large sizes and is sprinkled from the facility's inlet. The diameter of the crushed millet ranges from 
$0.22 \mathrm{~mm}$ to $0.45 \mathrm{~mm}$. A Testo-445 multi-function measuring instrument is used to measure the air velocity and the pressure loss with a vane probe and a pressure probe. The measuring range of the vane probe is 0.6 to $40 \mathrm{~m} / \mathrm{s}$ and the corresponding accuracy is $\pm(0.2 \mathrm{~m} / \mathrm{s} \pm 1.5 \%$ of measurement value $)$ $(+0.6$ to $+40 \mathrm{~m} / \mathrm{s})$. The measuring range of the pressure probe is 0 to $10,000 \mathrm{~Pa}$ and the corresponding accuracy is $\pm 10 \mathrm{~Pa}(0$ to $+2000 \mathrm{~Pa})$ and $\pm 0.5 \%$ of measurement value $(+2000$ to $+10,000 \mathrm{~Pa})$.

Meanwhile, a semicircular steel tube is used to collect the crushed millet. The tube is inserted into the nine small holes one by one, representing the distribution of the ash particles. The weights of millet for the nine collections are measured by a METTLER-TOLEDO analytical balance. Figure 7 illustrates the 72 detection spots over the perforated plate. They are arranged in an $8 \times 9$ matrix and the characters A-I refer to the nine small holes used for the measurement.

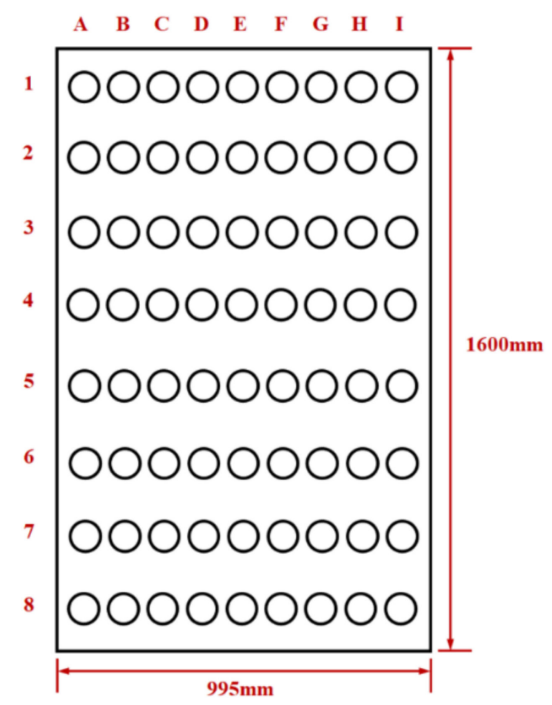

Figure 7. The sketch map of the detection spots over the perforated plate.

To avoid measurement error, variables are measured when the equipment runs to a relatively steady state. The experiments are repeated with deflector at different installing positions. Values of air velocity, pressure loss and weights of the crushed millet are recorded and analyzed. Comparisons are made between the results of the FMT experiments and CFD simulations.

\section{Results and Discussion}

\subsection{Particle Distributions with No Deflector}

Figure 8 illustrates the velocity distribution at plane 1 . The corresponding relative standard deviation (RSD) is $9.93 \%$ and the total pressure loss is $513.90 \mathrm{~Pa}$, including the two catalyst layers of $420 \mathrm{~Pa}$. Figure 9 shows the velocity distribution of the central section for the SCR-deNO $\mathrm{S}_{x}$ facility. As can be seen, the flue gas gathers towards the right-side wall of the vertical duct. The high-speed areas locate in the bottom side of the sloped duct and in the lower side of the vertical duct. 


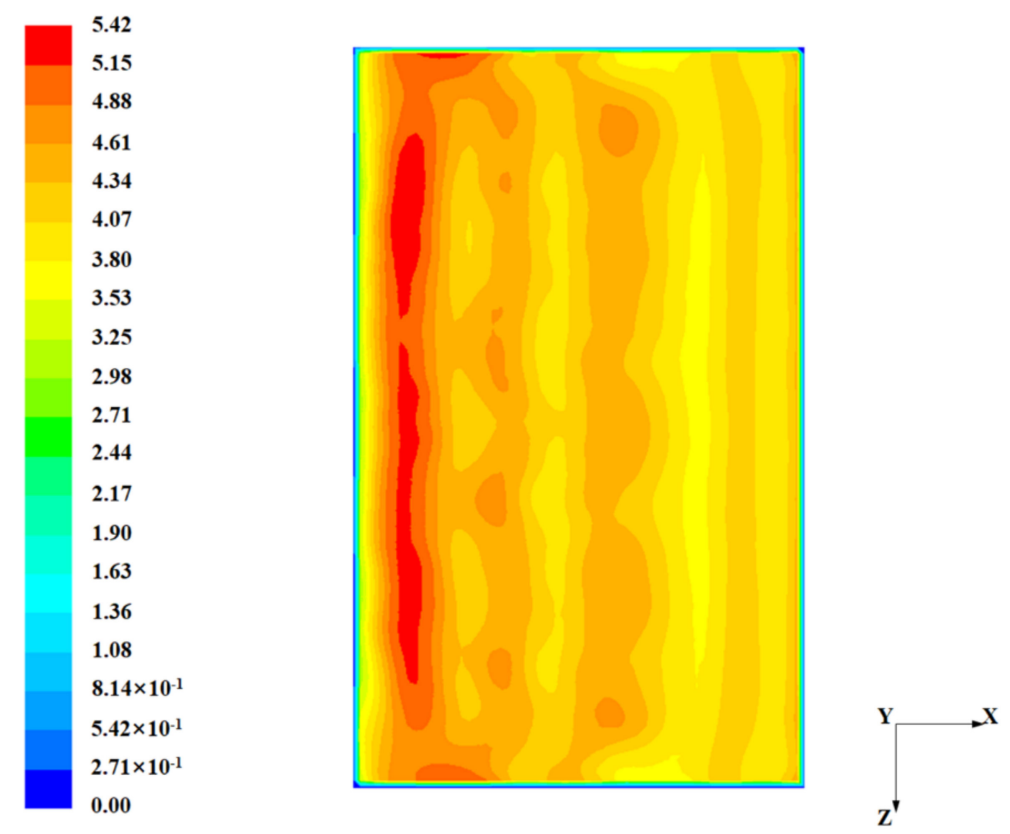

Figure 8. Contours of gas velocity at plane 1 with no deflector (unit: $\mathrm{m} / \mathrm{s}$ ).

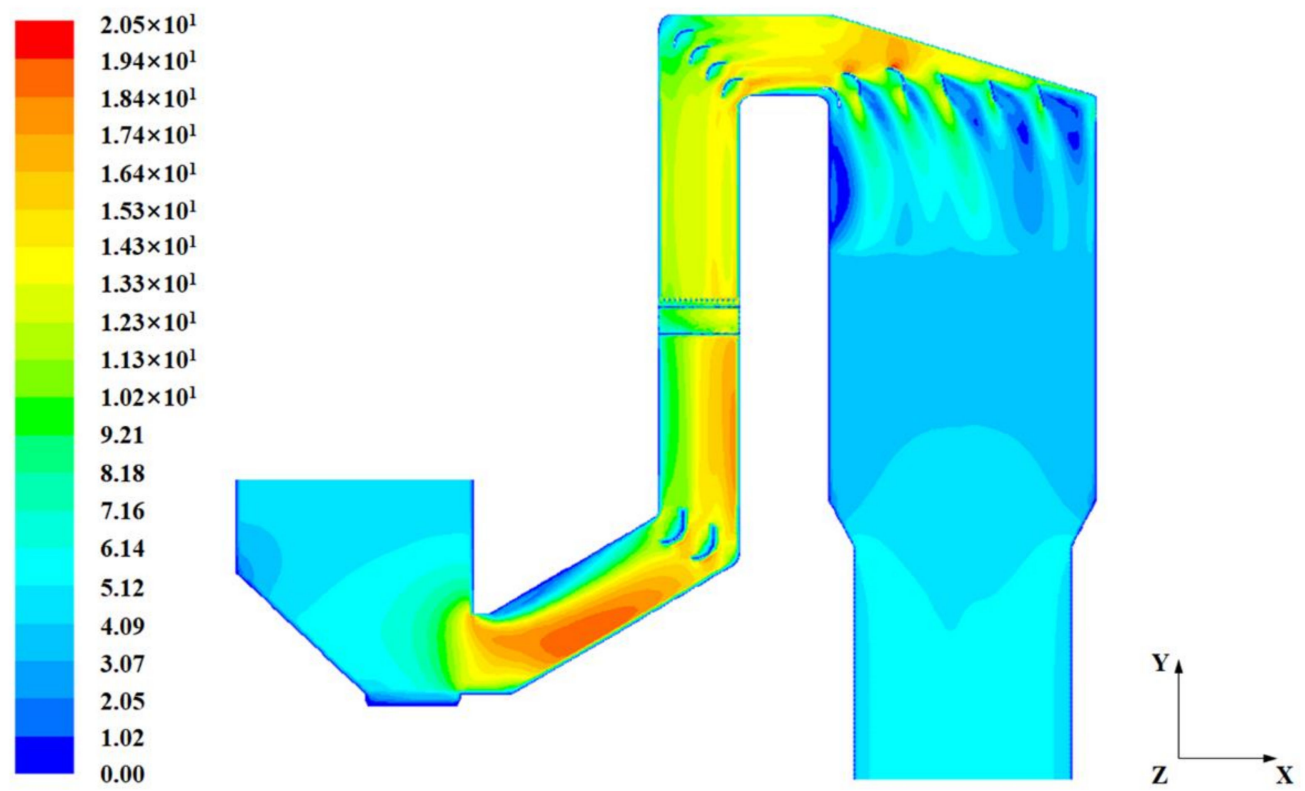

Figure 9. Contours of gas velocity at the central section (unit: m/s).

Figure $10 \mathrm{a}, \mathrm{b}$ show the general ash particle distributions of plane 1 and plane 2 with no deflector installed. The corresponding histogram graphs of ash particle distributions along the $\mathrm{X}$-direction and Z-direction are presented in Figures 11 and 12, respectively. 


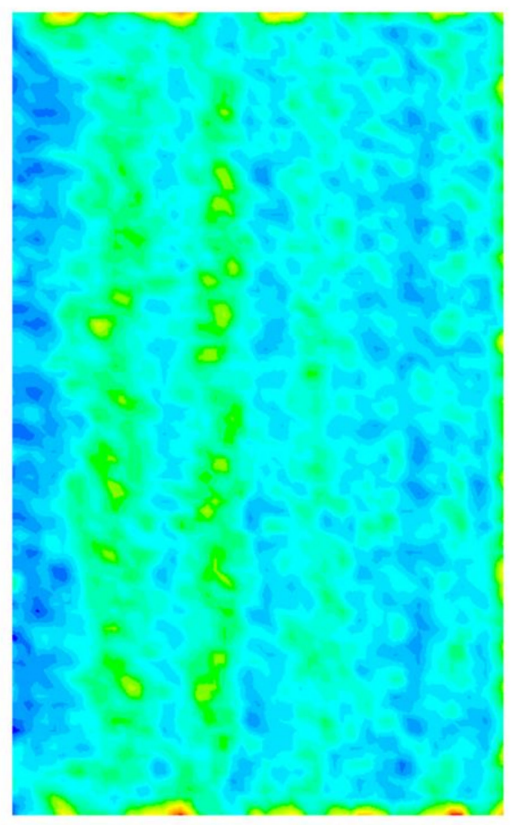

(a)

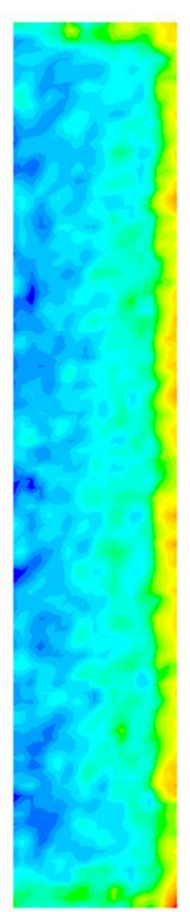

(b)
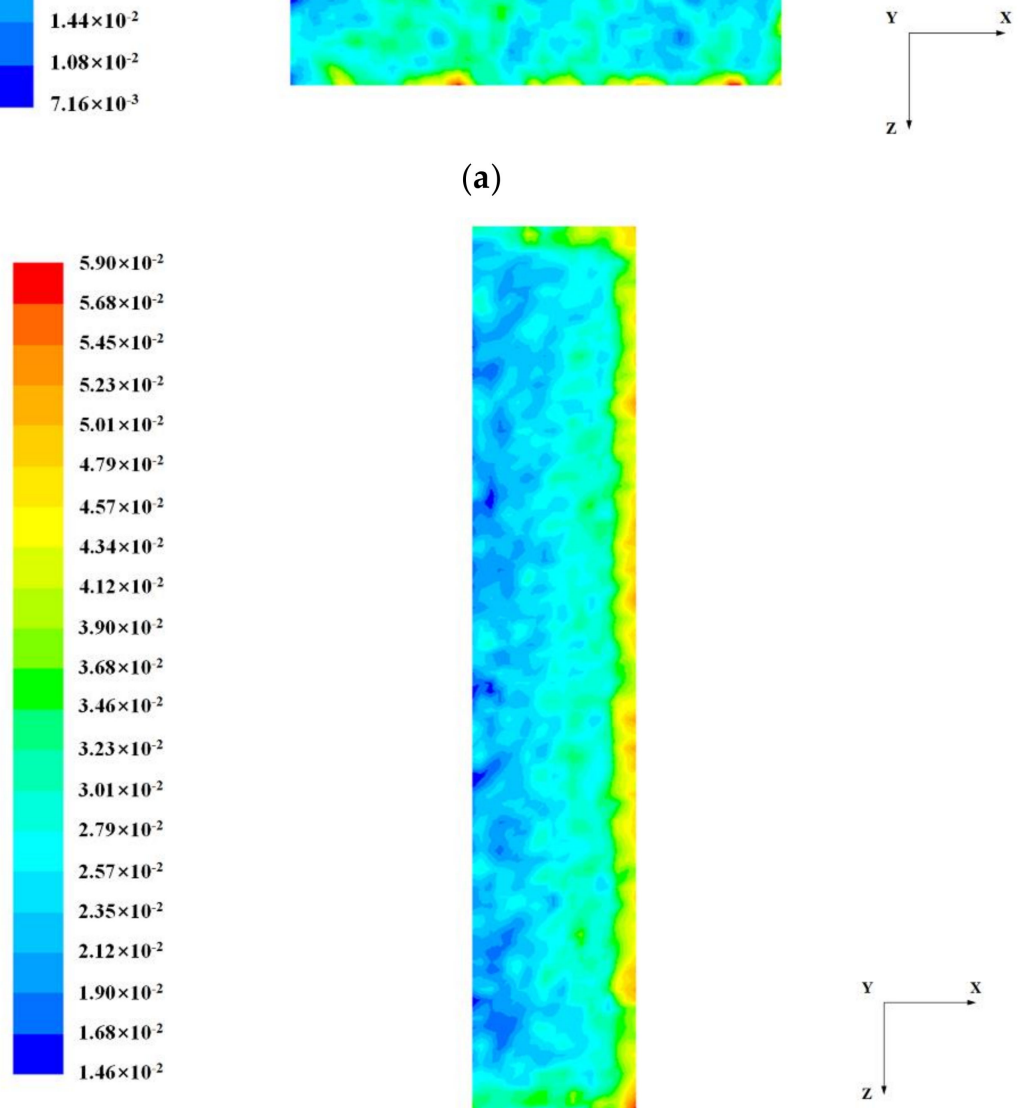

Figure 10. Contours of particle concentration: (a) plane 1, (b) plane 2 (unit: $\mathrm{g} / \mathrm{m}^{3}$ ). 


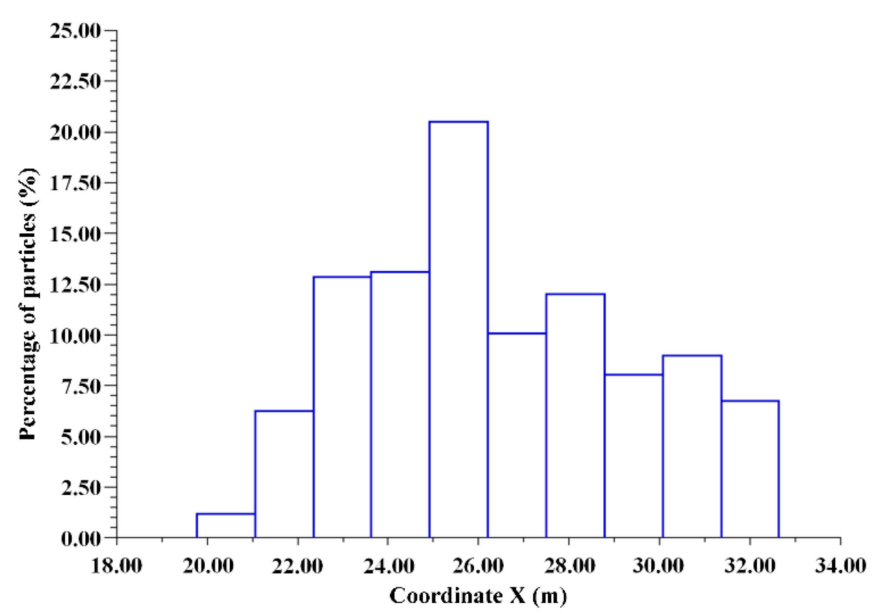

(a)

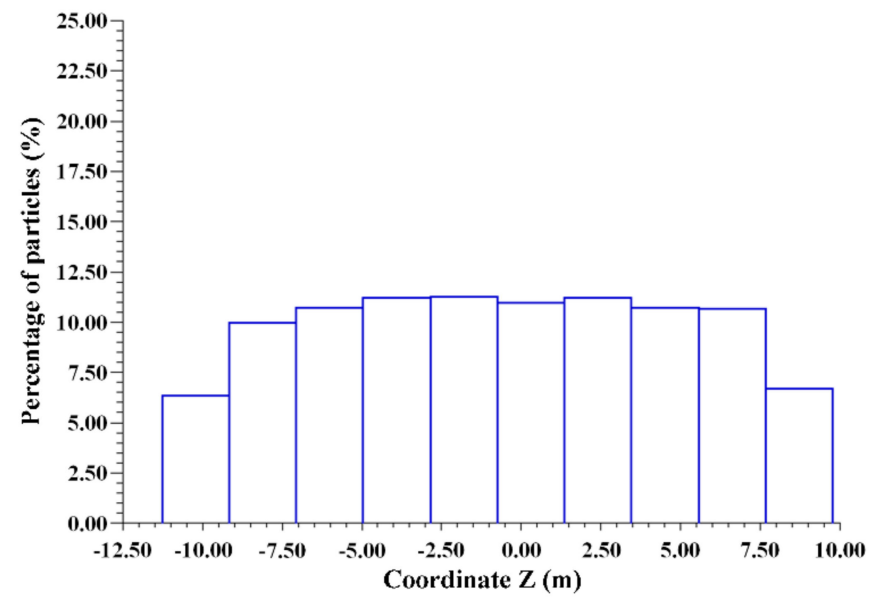

(b)

Figure 11. Histogram graphs of particle distributions at plane 1: (a) along the X-direction, (b) along the Z-direction.

As shown in Figure 11, there are 10 columns in both the X-direction and the Z-direction. It is indicated that the ash particle distribution is generally homogeneous in the Z-direction. Although the numbers of ash particles near the wall are relatively small, most of the percentages are close to the average level of $10 \%$. However, an obviously inhomogeneous distribution of ash particle is observed along the X-direction. The deviation between the maximum and the minimum is about 20 percentage points. It is revealed that the ash particles are accumulated near the central area of the plane, especially in the fifth column. On the contrary, the amount of ash particles is quite small in the first and second columns, indicating that few ash particles are accumulated near the left-side wall, which is corresponding to the inner side of the wedge-shaped turning. Similarly, for the ash particles at plane 2, the distribution is relatively homogeneous along the Z-direction while it is quite inhomogeneous along the $\mathrm{X}$-direction. According to Figure 12a, a severe accumulation of ash particles occurs near the right-side wall along the $\mathrm{X}$-direction, which may lead to a drastic impact on the AIG and the support structure. 


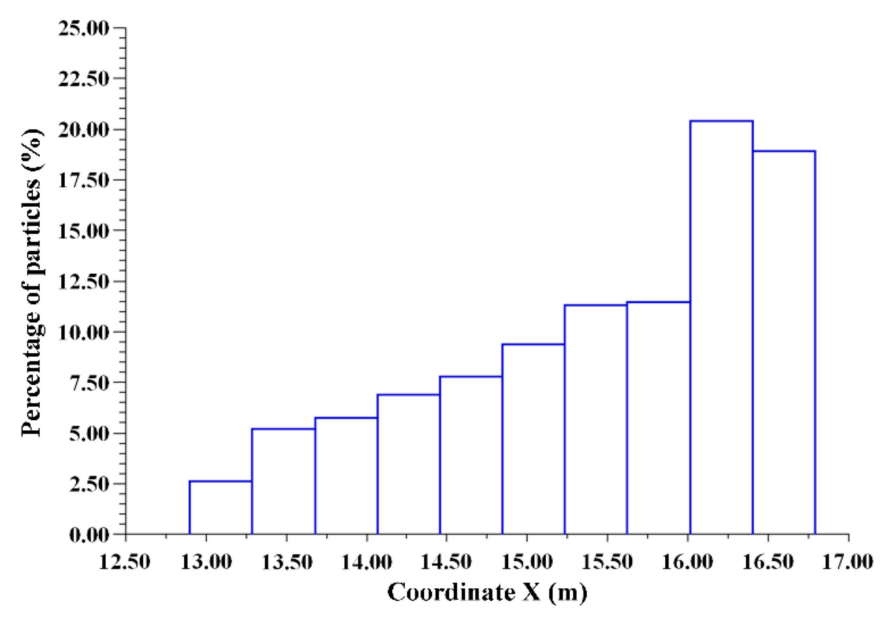

(a)

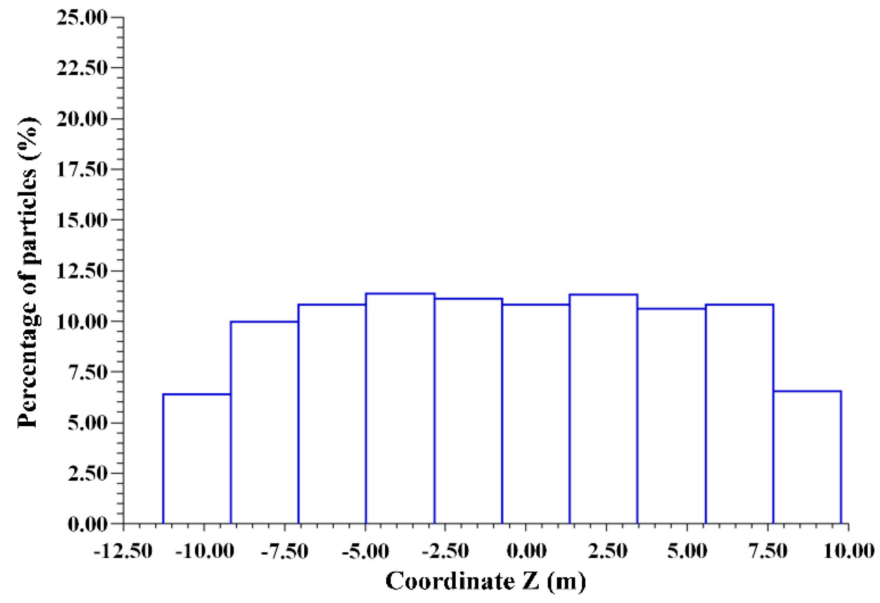

(b)

Figure 12. Histogram graphs of particle distributions at plane 2: (a) along the X-direction, (b) along the Z-direction.

A further investigation is conducted on the distributions of ash particles with different diameters. According to Table 1, the ash particles are classified into four classes based on the diameters: the small-sized particles $\left(\Phi \leq 6.3 \times 10^{-2} \mathrm{~mm}\right)$, the medium-sized particles $\left(6.3 \times 10^{-2} \mathrm{~mm}<\Phi \leq\right.$ $\left.8.8 \times 10^{-2} \mathrm{~mm}\right)$, the large-sized particles $\left(8.8 \times 10^{-2} \mathrm{~mm}<\Phi \leq 0.15 \mathrm{~mm}\right)$ and the extra-large-sized particles $(\Phi>0.15 \mathrm{~mm})$. Since the diameter distribution follows the Rosin-Rammler rule, the proportion of the particle numbers for the three groups is about 4:2:3:1. Figure 13 illustrates the distributions of the four classes of particles at plane 1 with no deflector installed.

According to Figure 13, it is indicated that the small-sized particles, which is shown in black dash, are well dispersed. Meanwhile, there is a similar tendency between the distributions of the large-sized and extra-large-sized particles, which are illustrated in blue and magenta, respectively. These two classes of ash particles perform extremely nonuniform distributions, especially for the extra-large-sized particles, the severest accumulation accounts for nearly $40 \%$ of the total amount. Moreover, few ash particles are accumulated near the left-side wall of plane 1 . Generally speaking, for the classic $\pi$-type SCR-deNO ${ }_{x}$ facilities, the particle accumulation is considered to occur on one side of the catalysts' entrance, which corresponds to the inner side of the wedge-shaped turning. This is in accordance with the former studies presented by $\mathrm{Xu}$ et al. [24] and Yu et al. [25]. With the diameter increases, a notable accumulation is observed and the distribution has a tendency to move towards the central area of the plane. Accordingly, it is revealed that the nonuniform particle distributions in Figures 11a and 12a are mainly attributed to the accumulation of the large-sized and extra-large-sized particles, which 
are larger than $8.8 \times 10^{-2} \mathrm{~mm}$. Attention should be paid to disperse the ash particles with relatively large sizes since they may be an important contributor to the particle accumulation. Furthermore, it is necessary to study the installation of the deflector, aiming to reduce the accumulation of the particles with relatively large sizes.

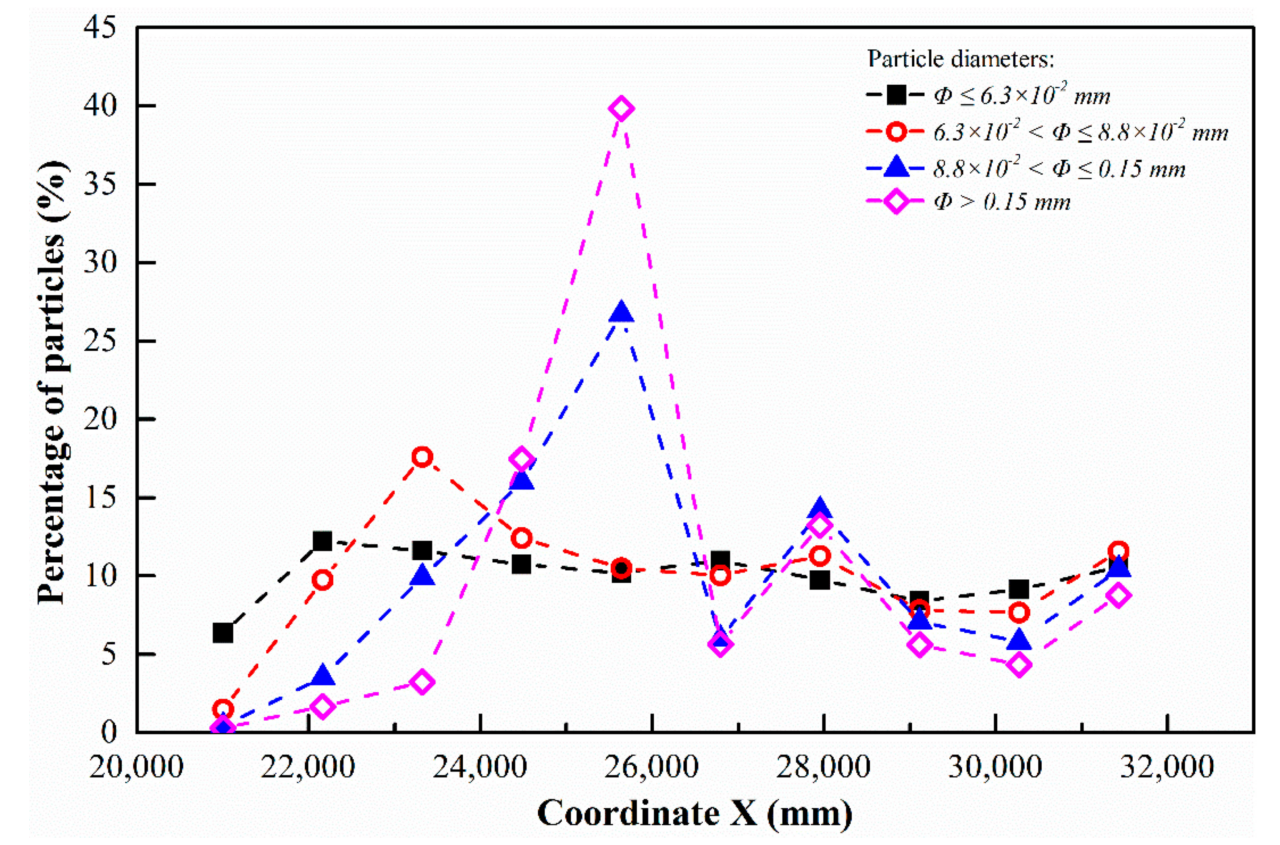

Figure 13. The distributions of the four classes of particles at plane 1 with no deflector installed.

\subsection{Optimization of the Triangular Deflector}

Considering the particle accumulation in Figures 11 and 12, the triangular deflector is installed on the right-side wall of the vertical duct. With a fixed installing position, the optimal design of the triangular deflector is carried out for the angle against the wind and the height. Lower RSD of velocity and total pressure loss are preferred while determining the optimal design.

Figure 14 shows the RSDs of velocity at plane 1 and the total pressure losses for deflectors with different angle against the wind. As shown in Figure 14, when the height is maintained to be $300 \mathrm{~mm}$, no obvious impact is observed for the RSDs with different angle against the wind. However, when the angle increases, the total pressure loss increases as well. There is a deviation of 9.70 Pa between the pressure losses with the angles of $10^{\circ}$ and $60^{\circ}$. Meanwhile, for the deflectors with the angles of $10^{\circ}$ and $15^{\circ}$, the total pressure losses are close and the corresponding distributions of particles larger than $8.8 \times 10^{-2} \mathrm{~mm}$ are nearly the same, as shown in Figure 15. Considering the machining difficulty and the material consumption, the angle against the wind of $15^{\circ}$ is adopted. 


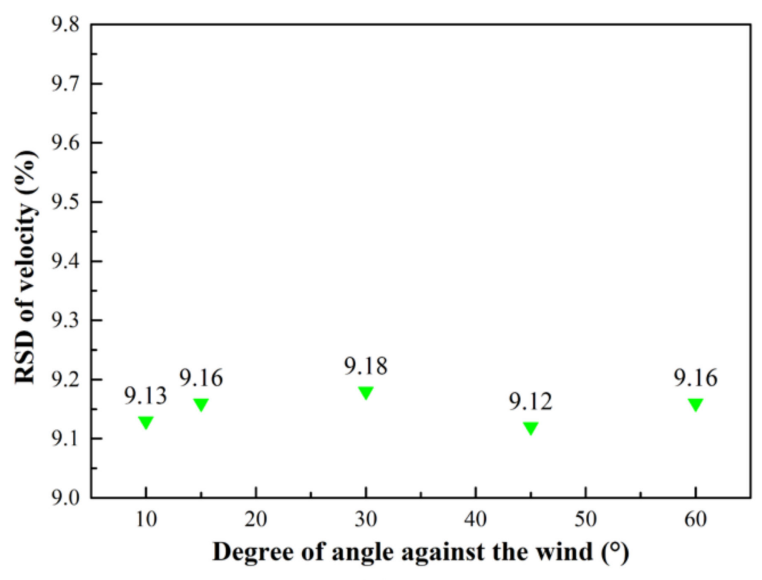

(a)

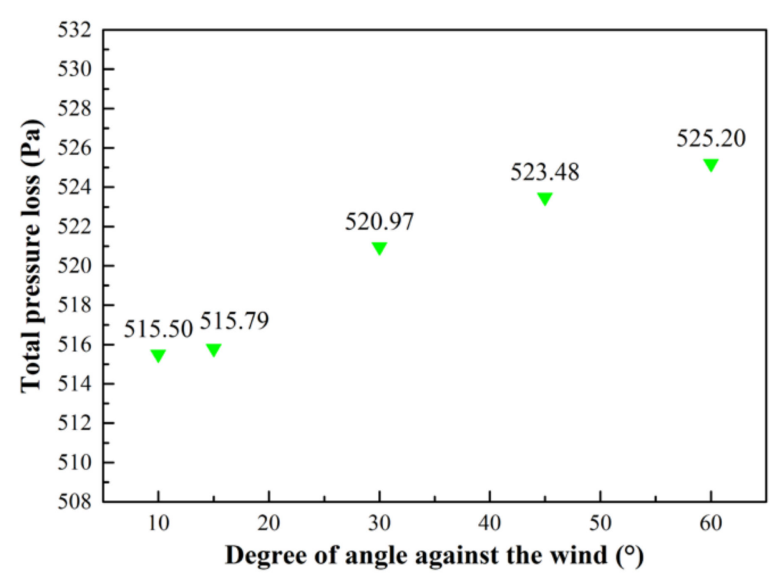

(b)

Figure 14. Statistical indices for deflectors with different angles against the wind: (a) the relative standard deviation (RSDs) of velocity, (b) the total pressure loss.

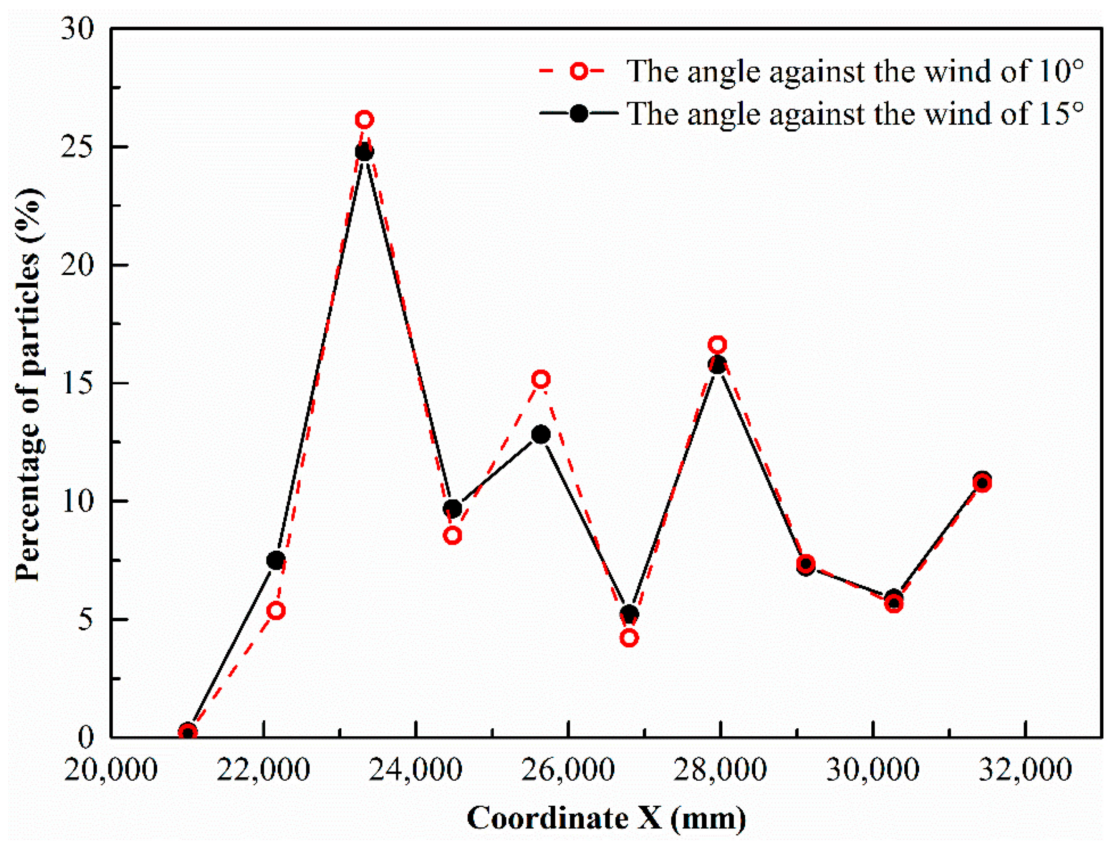

Figure 15. The distributions of the particles larger than $8.8 \times 10^{-2} \mathrm{~mm}$ for the deflectors of different angles.

Figure 16 shows the RSDs of velocity at plane 1 and the total pressure losses for different heights of the deflector. It is indicated that with a fixed angle against the wind of $15^{\circ}$, the RSDs increase slightly for the deflectors of $500 \mathrm{~mm}$ and $700 \mathrm{~mm}$, whereas the corresponding pressure losses increase noticeably. Figure 17 shows the distributions of particles larger than $8.8 \times 10^{-2} \mathrm{~mm}$ for the deflectors of $100 \mathrm{~mm}, 200 \mathrm{~mm}, 300 \mathrm{~mm}$. The corresponding RSDs of the particles are $86.61 \%, 81.49 \%, 67.49 \%$, respectively. It is revealed that the deflector with a height of $300 \mathrm{~mm}$ provides the best dispersal effect among the three deflectors. 


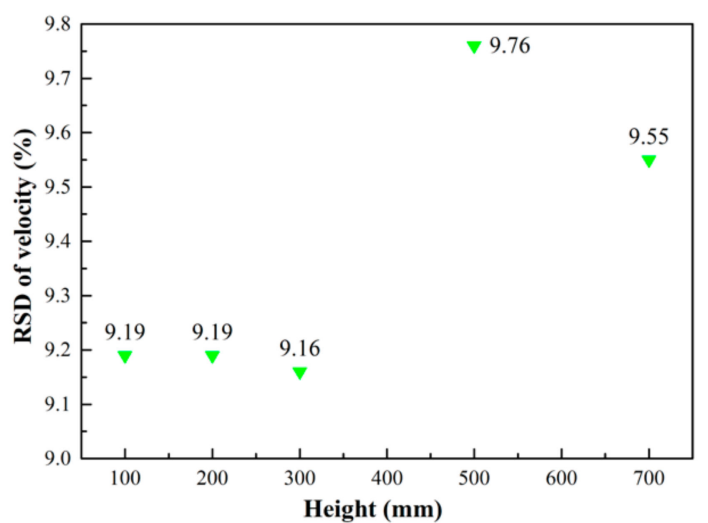

(a)

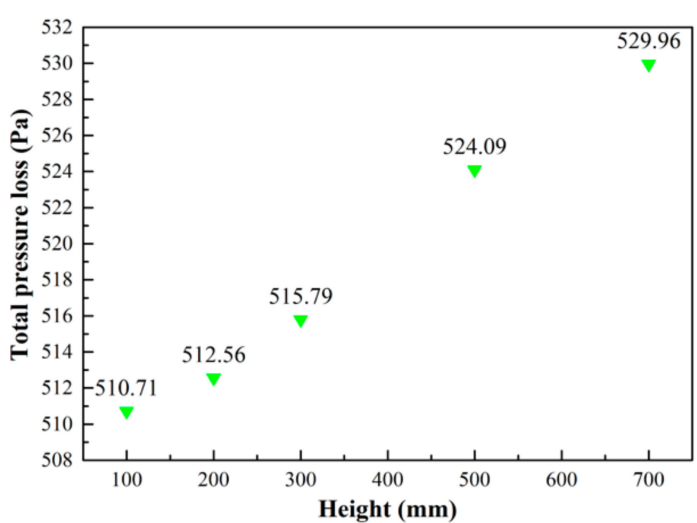

(b)

Figure 16. Statistical indices for deflectors with different heights: (a) the RSDs of velocity, (b) the total pressure loss.

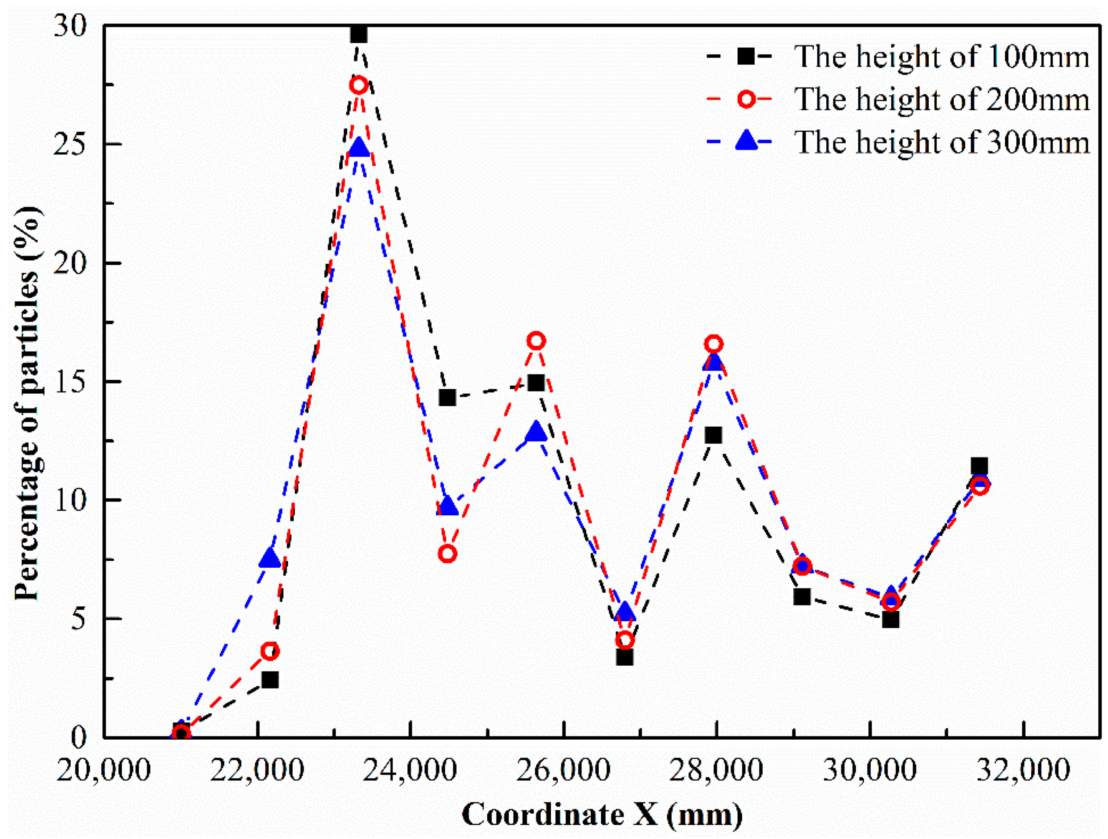

Figure 17. The distributions of the particles larger than $8.8 \times 10^{-2} \mathrm{~mm}$ for the deflectors of different heights.

Consequently, the angle against the wind of $15^{\circ}$ and the height of $300 \mathrm{~mm}$ are adopted for the triangular deflector.

\subsection{Particle Distributions with Different Installing Positions of the Deflector}

Figure 18 illustrates the particle distributions at plane 1 with the low deflector installation, the middle deflector installation and the high deflector installation, respectively. To make comparisons, Figure 13, which presents the particle distribution with no deflector installed, is illustrated here as Figure 18a. Tables 2 and 3 give the statistical indices of the particle distributions corresponding to Figure 18. The RSD is used to represent the uniformity of ash particle distributions. 


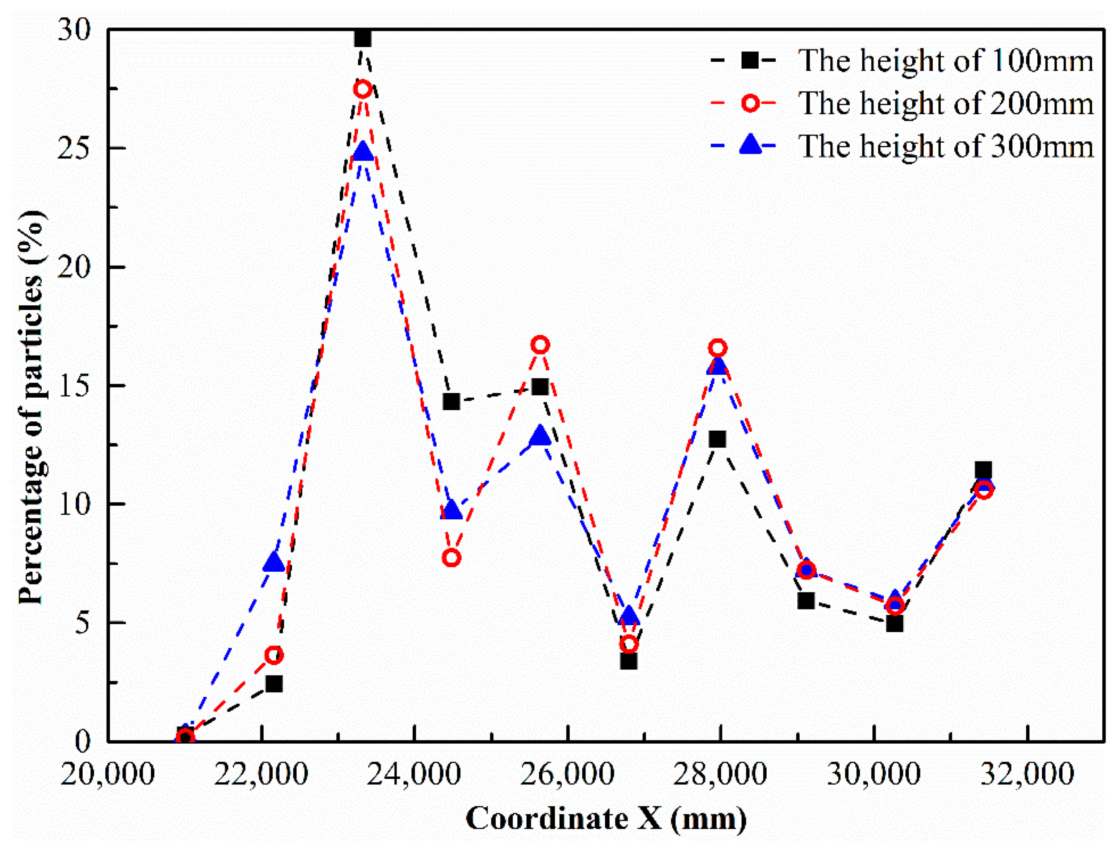

Figure 18. The distributions of the four classes of particles at plane 1 with different installing positions of the triangular deflector: (a) no deflector installed, (b) the low deflector installation, (c) the middle deflector installation, and (d) the high deflector installation.

Table 2. The RSDs of distributions for small-sized, medium-sized, large-sized and extra-large-sized particles at plane 1 with different installing positions of the triangular deflector.

\begin{tabular}{ccccc}
\hline Case & $\begin{array}{c}\text { Small-Sized } \\
\text { Particles }\end{array}$ & $\begin{array}{c}\text { Medium-Sized } \\
\text { Particles }\end{array}$ & $\begin{array}{c}\text { Large-Sized } \\
\text { Particles }\end{array}$ & $\begin{array}{c}\text { Extra-Large-Sized } \\
\text { Particles }\end{array}$ \\
\hline $\begin{array}{c}\text { No deflector } \\
\text { installed } \\
\text { Low deflector } \\
\text { installation } \\
\text { Middle deflector } \\
\text { installation }\end{array}$ & $16.97 \%$ & $40.94 \%$ & $75.25 \%$ & $117.29 \%$ \\
$\begin{array}{c}\text { High deflector } \\
\text { installation }\end{array}$ & $17.39 \%$ & $43.60 \%$ & $61.73 \%$ & $66.12 \%$ \\
\hline
\end{tabular}

Table 3. The maximum percentages of small-sized, medium-sized, large-sized and extra-large-sized particles at plane 1 with different installing positions of the triangular deflector.

\begin{tabular}{ccccc}
\hline Case & $\begin{array}{c}\text { Small-Sized } \\
\text { Particles }\end{array}$ & $\begin{array}{c}\text { Medium-Sized } \\
\text { Particles }\end{array}$ & $\begin{array}{c}\text { Large-Sized } \\
\text { Particles }\end{array}$ & $\begin{array}{c}\text { Extra-Large-Sized } \\
\text { Particles }\end{array}$ \\
\hline $\begin{array}{c}\text { No deflector } \\
\text { installed } \\
\begin{array}{c}\text { Low deflector } \\
\text { installation } \\
\text { Middle deflector } \\
\text { installation }\end{array}\end{array}$ & $12.21 \%$ & $17.58 \%$ & $26.73 \%$ & $39.84 \%$ \\
$\begin{array}{c}\text { High deflector } \\
\text { installation }\end{array}$ & $12.72 \%$ & $18.45 \%$ & $21.70 \%$ & $20.59 \%$ \\
\hline
\end{tabular}

Generally, it is indicated that the installation of the triangular deflector cannot substantially improve the distributions of small-sized and medium-sized particles, while it plays a positive role in reducing the accumulation of the large-sized and extra-large-sized particles. Although the performance varies from each other among Figure $18 \mathrm{~b}-\mathrm{d}$, the accumulated large-sized and extra-large-sized particles 
are dispersed and the corresponding maximum percentage decreases. The installation of the triangular deflector may not only disperse particles itself but also reduce the momentum of the particles. When passing the turnings in the downstream side, the particles larger than $8.8 \times 10^{-2} \mathrm{~mm}$ possess fewer inertia and are unable to accumulate easily in the area near the central line of plane 1.

As shown in Tables 2 and 3, the low deflector installation gives the best performance on reducing the accumulation of large-sized and extra-large-sized particles. Compared with Figure 18a, which shows the particle distribution without the deflector, the maximum percentages of the accumulated large-sized and extra-large-sized particles decrease from $26.73 \%$ to $21.70 \%$ and from $39.84 \%$ to $20.59 \%$, respectively, which is better than the middle and high deflector installations. Besides, the RSDs of the large-sized and extra-large-sized particles with the low deflector installation are $61.73 \%$ and $66.12 \%$, which is the smallest among the four cases.

Likewise, investigations are also conducted on the particle distributions at plane 2. Figure 19 shows the corresponding distributions with different installing configurations of the deflector. It is indicated that the installation of the deflector has a notable performance on reducing the particle accumulation near the right-side wall. However, the ash particles cannot be dispersed effectively to the left side of plane 2. This is mainly due to the limitation of the height of the triangular deflector. Enlarging the deflector will lead to the increase of the total pressure loss.

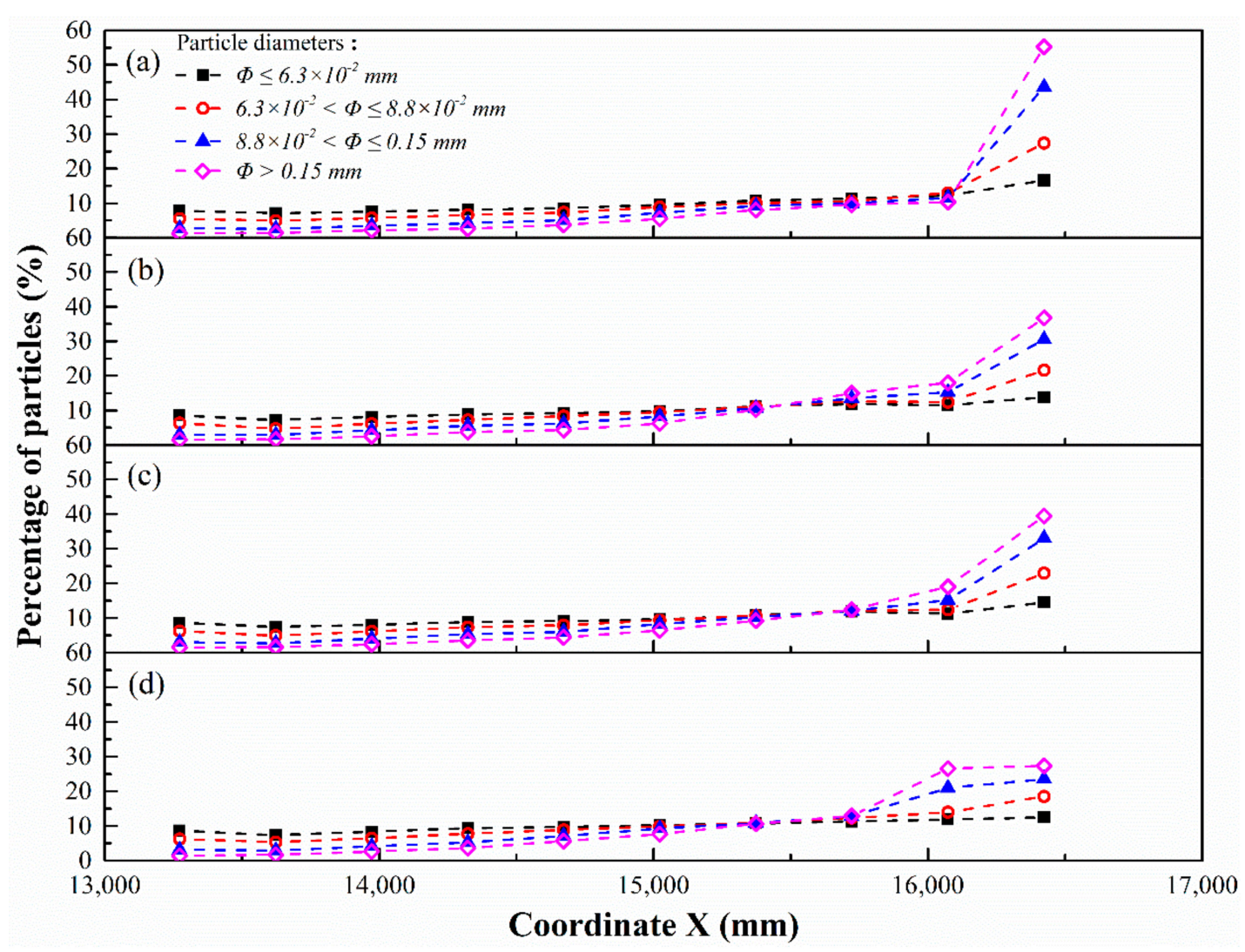

Figure 19. The distributions of the four classes of particles at plane 2 with different installing positions of the triangular deflector: (a) no deflector installed, (b) the low deflector installation, (c) the middle deflector installation, and (d) the high deflector installation.

Tables 4 and 5 show the statistical indices of the particle distributions corresponding to Figure 19. The high deflector installation seems to reduce the accumulation remarkably. This is because the deflector is installed near the observation plane, which improves the dispersal effect. Meanwhile, the high deflector installation cannot achieve a satisfying performance on reducing the accumulation of plane 1, as can be seen from Tables 2 and 3. Hence, the low deflector installation may be an optimal choice. 
Table 4. The RSDs of distributions for small-sized, medium-sized, large-sized and extra-large-sized particles at plane 2 with different installing positions of the triangular deflector.

\begin{tabular}{ccccc}
\hline Case & $\begin{array}{c}\text { Small-Sized } \\
\text { Particles }\end{array}$ & $\begin{array}{c}\text { Medium-Sized } \\
\text { Particles }\end{array}$ & $\begin{array}{c}\text { Large-Sized } \\
\text { Particles }\end{array}$ & $\begin{array}{c}\text { Extra-Large-Sized } \\
\text { Particles }\end{array}$ \\
\hline $\begin{array}{c}\text { No deflector } \\
\text { installed }\end{array}$ & $29.04 \%$ & $66.36 \%$ & $122.05 \%$ & $162.57 \%$ \\
$\begin{array}{c}\text { Low deflector } \\
\text { installation } \\
\text { Middle deflector } \\
\text { installation }\end{array}$ & $20.08 \%$ & $48.87 \%$ & $83.92 \%$ & $109.99 \%$ \\
$\begin{array}{c}\text { High deflector } \\
\text { installation }\end{array}$ & $21.08 \%$ & $52.24 \%$ & $90.58 \%$ & $117.44 \%$ \\
\hline
\end{tabular}

Table 5. The maximum percentages of small-sized, medium-sized, large-sized and extra-large-sized particles at plane 2 with different installing positions of the triangular deflector.

\begin{tabular}{ccccc}
\hline Case & $\begin{array}{c}\text { Small-Sized } \\
\text { Particles }\end{array}$ & $\begin{array}{c}\text { Medium-Sized } \\
\text { Particles }\end{array}$ & $\begin{array}{c}\text { Large-Sized } \\
\text { Particles }\end{array}$ & $\begin{array}{c}\text { Extra-Large-Sized } \\
\text { Particles }\end{array}$ \\
\hline $\begin{array}{c}\text { No deflector } \\
\text { installed } \\
\text { Low deflector } \\
\text { installation } \\
\text { Middle deflector } \\
\text { installation }\end{array}$ & $16.65 \%$ & $27.41 \%$ & $43.55 \%$ & $55.28 \%$ \\
$\begin{array}{c}\text { High deflector } \\
\text { installation }\end{array}$ & $13.82 \%$ & $21.61 \%$ & $30.53 \%$ & $36.78 \%$ \\
\hline
\end{tabular}

Furthermore, combined with the central sectional contour shown in Figure 9, it is indicated that the low deflector installation is located in the high-speed area of the flow field in the vertical duct. Therefore, installing the triangular deflectors in the high-speed area of the vertical duct may be an efficient way to disperse particles with relatively large sizes and reduce particle accumulation at the entrance of the catalysts.

Figure 20 illustrates the velocity distribution of plane 1 corresponding to the low deflector installation. The RSD of velocity is $8.30 \%$ and the total pressure loss is $518.91 \mathrm{~Pa}$, including the two catalyst layers of $420 \mathrm{~Pa}$. Compared with Figure 8, it reveals that the low deflector installation has no drastic impact on the velocity distribution and the total pressure loss.
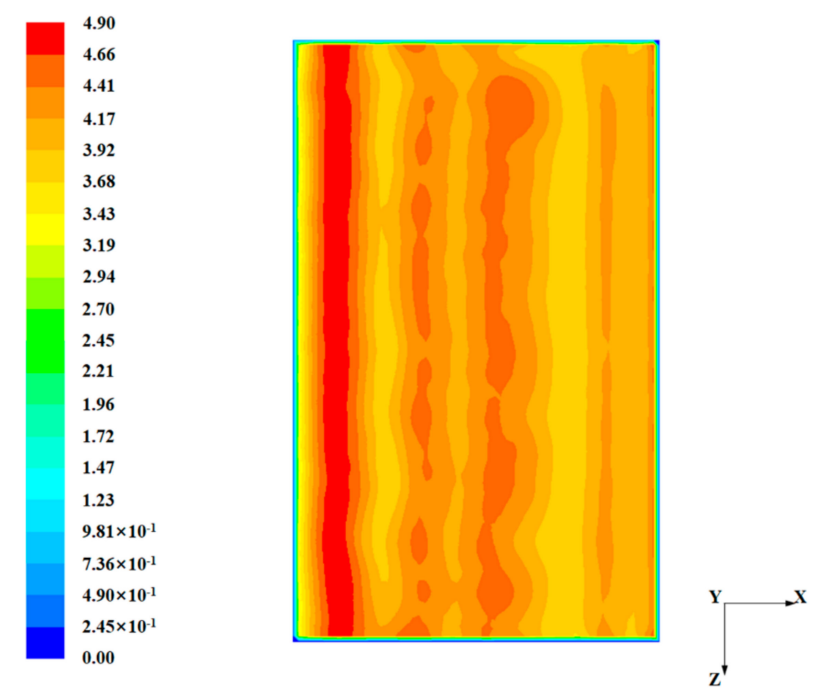

Figure 20. Contours of gas velocity at plane 1 with the low deflector installation (unit: $\mathrm{m} / \mathrm{s}$ ). 


\subsection{FMT Validation}

Table 6 displays the measured weights of the crushed millet in the FMT. Figure 21 illustrates the particle distribution over the perforated plate and Table 7 gives the corresponding statistical indices.

Table 6. Measured weights of the crushed millet in the FMT (unit: g).

\begin{tabular}{|c|c|c|c|c|c|c|c|c|c|}
\hline \multirow{2}{*}{ Case } & \multicolumn{9}{|c|}{ Position of the Detection Holes } \\
\hline & $\mathbf{A}$ & B & $\mathrm{C}$ & D & E & $\mathbf{F}$ & G & $\mathbf{H}$ & $\mathbf{I}$ \\
\hline $\begin{array}{l}\text { No deflector } \\
\text { installed }\end{array}$ & 8.1939 & 6.2764 & 3.6915 & 16.0562 & 33.2517 & 16.5015 & 7.5442 & 7.3632 & 14.7715 \\
\hline $\begin{array}{l}\text { Low deflector } \\
\text { installation }\end{array}$ & 6.3363 & 6.7788 & 3.1165 & 11.9148 & 10.3647 & 4.2281 & 9.2913 & 6.9905 & 8.6209 \\
\hline $\begin{array}{l}\text { Middle deflector } \\
\text { installation }\end{array}$ & 5.1246 & 4.3803 & 2.3775 & 15.3987 & 11.1882 & 9.4037 & 7.1723 & 3.6794 & 9.6139 \\
\hline $\begin{array}{l}\text { High deflector } \\
\text { installation }\end{array}$ & 8.2276 & 5.7866 & 5.0182 & 28.6073 & 2.4682 & 14.2543 & 13.4807 & 7.9573 & 15.9467 \\
\hline
\end{tabular}

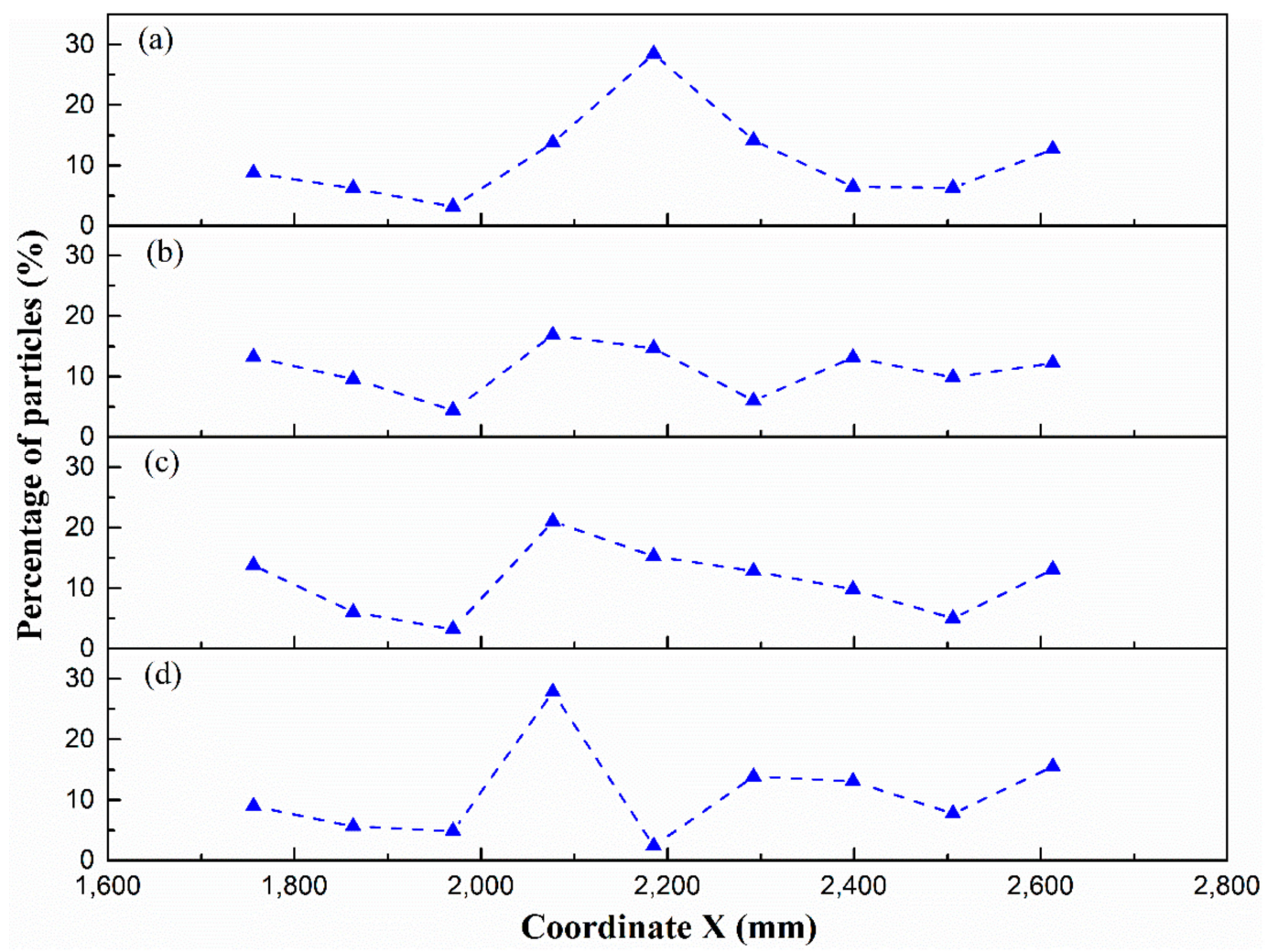

Figure 21. The distributions of crushed millet over the perforated plate with different installing positions of the triangular deflector: (a) no deflector installed, (b) the low deflector installation, (c) the middle deflector installation, and (d) the high deflector installation.

Table 7. The RSDs and the maximum percentages of the crushed millet's weight over the perforated plate with different installing positions of the triangular deflector.

\begin{tabular}{ccc}
\hline Case & RSD & Maximum Percentage \\
\hline No deflector installed & $68.12 \%$ & $28.51 \%$ \\
Low deflector installation & $36.36 \%$ & $16.87 \%$ \\
Middle deflector installation & $50.94 \%$ & $21.00 \%$ \\
High deflector installation & $69.10 \%$ & $27.84 \%$ \\
\hline
\end{tabular}

According to Figure 21a, when no additional deflector exists, it indicates that the crushed millet accumulates in the central area of the plane. The corresponding maximum percentage of the 
accumulation is $28.51 \%$. Nonetheless, after installing the triangular deflector, it is easy to find that all the distributions have moved towards the left side of the plane. Although no evident improvement of uniformity is achieved by the high deflector installation, the accumulation is dispersed noticeably for the low deflector installation. The maximum percentage of the accumulated millet with the low deflector installation is $16.87 \%$ and the RSD is $36.36 \%$, demonstrating that the low deflector installation is effective in reducing the accumulation during the FMT.

Compared with the blue lines and magenta lines in Figure 18, the experimental results show a similar tendency on the distributions of the large-sized and extra-large-sized particles, which are classified as the particles larger than $8.8 \times 10^{-2} \mathrm{~mm}$. In other words, the effects of different deflector installations on dispersing the particles are in accordance with the simulation results of the particles larger than $8.8 \times 10^{-2} \mathrm{~mm}$. It can be observed that the maximum spots occurred at different positions on the coordinate to some extent. Generally speaking, the experimental results have a deviation towards the right side and a slight accumulation near the left-side wall. This may be attributed to the sampling process and the usage of the crushed millet. Measurement errors are caused by the collection through the detection holes. Besides, the crushed millet ranging from $0.22 \mathrm{~mm}$ to $0.45 \mathrm{~mm}$ contains more inertia, leading to the deviation to the right side. Some millet may be too heavy for the air to lift. Thus, accumulation occurs near the left-side wall after the crushed millet passes the turnings.

Table 8 shows the measured values of air velocity for the FMT with the low deflector installation. According to Table 8, the RSD is $9.20 \%$ and the corresponding pressure loss is $489 \mathrm{~Pa}$. The statistical indices of the FMT are in good agreement with the simulation results of the low deflector installation, which is shown in Figure 20.

Table 8. Measured values of air velocity for the FMT with the low deflector installation (unit: $\mathrm{m} / \mathrm{s}$ ).

\begin{tabular}{cccccccccc}
\hline Detection Spot & A & B & C & D & E & F & G & H & I \\
\hline 1 & 2.22 & 2.75 & 2.29 & 1.95 & 2.31 & 2.09 & 2.08 & 2.15 & 2.15 \\
2 & 2.60 & 2.74 & 2.30 & 1.99 & 2.15 & 2.13 & 2.10 & 2.67 & 2.31 \\
3 & 2.34 & 2.92 & 2.26 & 2.10 & 2.22 & 2.23 & 2.06 & 2.26 & 2.18 \\
4 & 2.23 & 2.62 & 2.31 & 2.15 & 2.43 & 2.32 & 2.12 & 2.26 & 2.37 \\
5 & 2.55 & 2.65 & 2.19 & 2.14 & 2.37 & 2.38 & 2.15 & 2.24 & 2.36 \\
6 & 2.52 & 2.81 & 2.15 & 2.27 & 2.56 & 2.50 & 2.23 & 2.60 & 2.30 \\
7 & 2.79 & 2.68 & 2.11 & 2.16 & 2.49 & 2.42 & 2.29 & 2.34 & 2.34 \\
8 & 2.44 & 2.48 & 2.03 & 2.14 & 2.48 & 2.21 & 2.21 & 2.54 & 2.25 \\
\hline
\end{tabular}

Qualitatively speaking, the FMT results are consistent with the simulation results of the large-sized and extra-large-sized particles. The corresponding distributions of the accumulated particles are similar. Meanwhile, it provides an indication that the optimized triangular deflector is an effective approach in reducing the accumulation of the ash particles with relatively large sizes. According to the experimental results, the low installation of the triangular deflector shows the best performance. It proves that the optimal installing position is in accordance with the simulation results, which is in the high-speed area of the vertical duct. Besides, it is revealed that the installation of the optimized deflector won't bring any drastic impact on the flow field of the SCR-deNO $x$ facility. On the other hand, there are still drawbacks for the implementation of the FMT. In this study, since the diameter range of the crushed millet is larger than $8.8 \times 10^{-2}-0.15 \mathrm{~mm}$, it is unable to represent the ash particles perfectly and can only provide qualitative analysis. Moreover, the distributions of the particles smaller than $8.8 \times 10^{-2} \mathrm{~mm}$ and the comparisons among the four classes of particles cannot be validated via the FMT experiments. Further study is needed and a more precise evaluation on the accumulated particles may be presented.

\section{Conclusions}

In this study, the particle dispersal approach for the SCR-deNO ${ }_{x}$ facility of a $1000 \mathrm{MW}$ coal-fired power plant was investigated. Evaluation was made on the accumulation of different-sized particles via CFD simulation. It was revealed that for the classic $\pi$-type SCR-deNO ${ }_{x}$ facilities, the particle 
accumulation predominantly occurred on one side of the catalysts' entrance, which corresponds to the inner side of the wedge-shaped turning, and the ash particles larger than $8.8 \times 10^{-2} \mathrm{~mm}$ were mainly responsible for the accumulation. A triangular deflector was optimized numerically and used to reduce the particle accumulation. According to the simulation results, installing the triangular deflector at the high-speed area of the vertical duct may be an efficient way to disperse the particles with relatively large sizes and reduce the accumulation. Statistical indices showed that after installing the deflector, the RSDs of the large-sized and extra-large-sized particles decreased from $75.25 \%$ to $61.73 \%$ and from $117.29 \%$ to $66.12 \%$, respectively. The corresponding maximum percentages of the accumulation decreased from $26.73 \%$ to $21.70 \%$ and from $39.84 \%$ to $20.59 \%$, respectively. FMT was carried out to validate the simulation results. The dispersal effect and the optimal installing position of the triangular deflector on particles with relatively large sizes were validated. This paper provides comprehensive investigations on particle accumulation and is a supplementary work for the former studies. The numerical and experimental results presented in this study may provide a good reference on reducing the particle accumulation and are valuable for further study. The proposed optimized triangular deflector along with its installing position were proven to be effective and can be easily implemented on high-dust SCR-deNO ${ }_{x}$ facilities.

Author Contributions: Conceptualization, H.Z.; Data curation, H.Z.; Formal analysis, H.Z.; Funding acquisition, J.Y.; Investigation, H.Z.; Methodology, H.Z. and J.Y.; Project administration, J.Y.; Resources, J.Y.; Supervision, J.Y.; Validation, H.Z. and J.W.; Writing—original draft, H.Z.; Writing—review and editing, J.Y.

Funding: This research was funded by the National Natural Science Foundation of China, grant number 61533013 and the Natural Science Foundation of Shanghai, grant number 17ZR1414200.

Conflicts of Interest: The authors declare no conflict of interest.

\section{Abbreviations}

$\begin{array}{ll}\text { AIG } & \text { Ammonia Injection Grid } \\ \text { BMCR } & \text { Boiler Maximum Continuous Rating } \\ \text { CFD } & \text { Computational Fluid Dynamics } \\ \text { DPM } & \text { Discrete Phase Model } \\ \text { FMT } & \text { Flow Model Test } \\ \text { RSD } & \text { Relative Standard Deviation } \\ \text { SCR } & \text { Selective Catalytic Reduction } \\ \text { RANS } & \text { Raynolds Averaged Navier Stokes } \\ \text { SIMPLE } & \text { Semi-Implicit Method for Pressure-Linked Equation }\end{array}$

\section{Appendix A}

In the following, the grid convergence analysis is presented. Considering the time consumption and the limitation of the hardware, the grid convergence analysis is conducted with two-dimensional meshing model, as shown in Figure A1. Figure A2 illustrates the velocity distribution at plane 1 with different grid sizes.

It is revealed that the distributions of the $100 \mathrm{~mm}$ grid and the $75 \mathrm{~mm}$ grid are nearly the same along the $\mathrm{X}$ direction. Hence, the $100 \mathrm{~mm}$ grid is appropriate to generate the meshing geometry. 


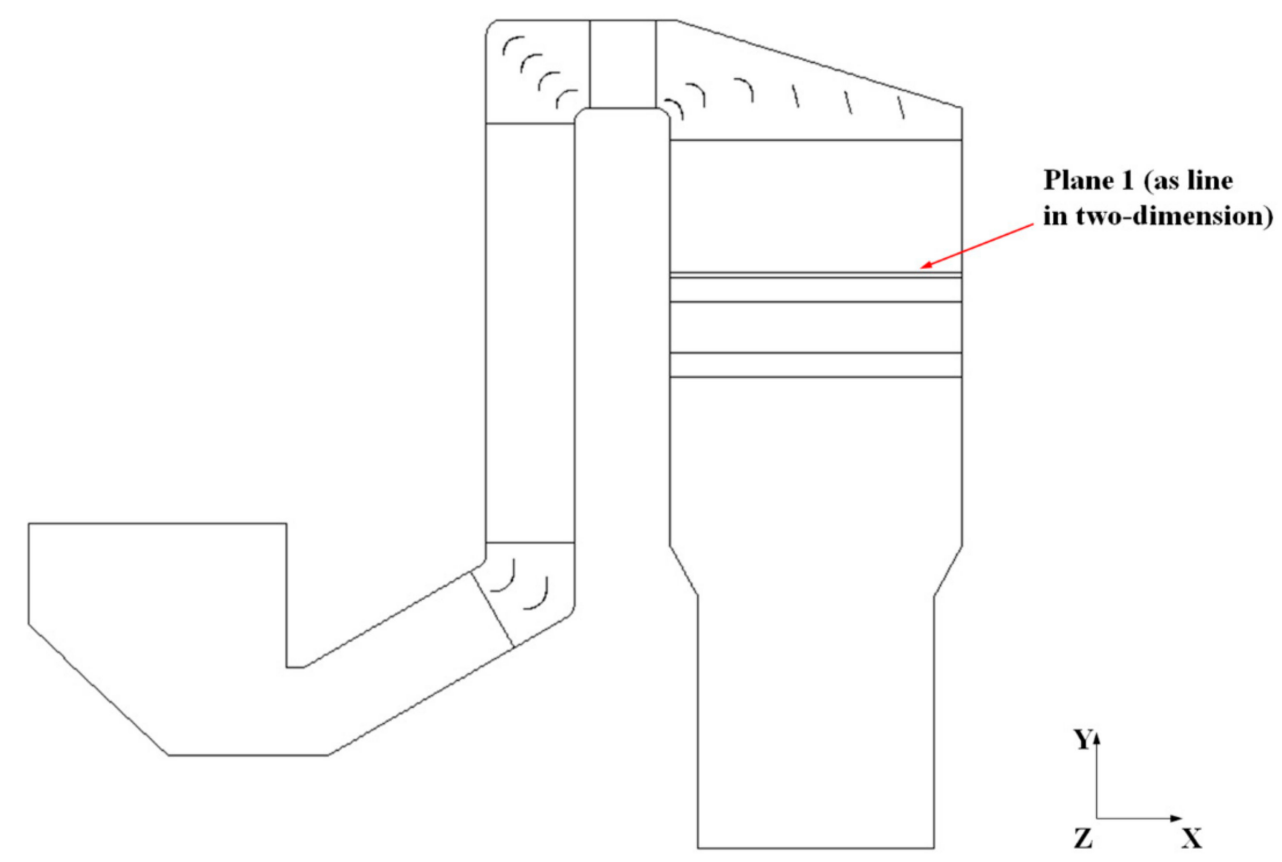

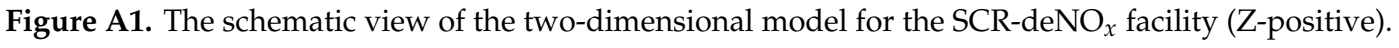

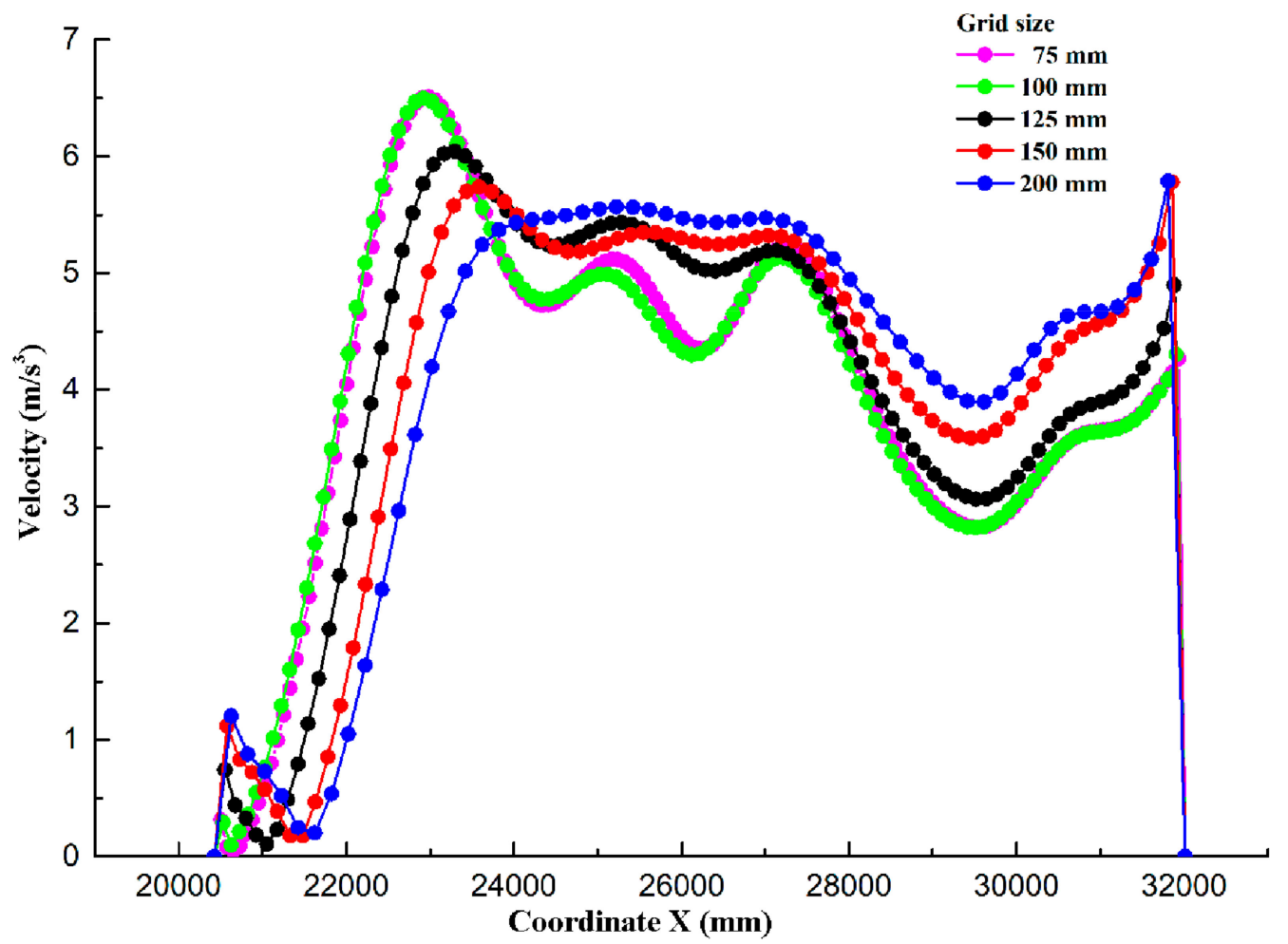

Figure A2. The velocity distributions at plane 1 with the two-dimensional model.

\section{References}

1. Skalska, K.; Miller, J.S.; Ledakowicz, S. Trends in $\mathrm{NO}_{x}$ abatement: A review. Sci. Total Environ. 2010, 408, 3976-3989. [CrossRef] [PubMed]

2. Gómez-García, M.A.; Pitchon, V.; Kiennemann, A. Pollution by nitrogen oxides: An approach to $\mathrm{NO}_{x}$ abatement by using sorbing catalytic materials. Environ. Int. 2005, 31, 445-467. [CrossRef] [PubMed] 
3. Crippa, M.; Guizzardi, D.; Muntean, M.; Schaaf, E.; Dentener, F.; van Aardenne, J.A.; Monni, S.; Doering, U.; Olivier, J.G.J.; Pagliari, V.; et al. Gridded emissions of air pollutants for the period 1970-2012 within EDGAR v4.3.2. Earth Syst. Sci. Data 2018, 10, 1987-2013. [CrossRef]

4. European Environment Agency. Emissions of the Main Air Pollutants in EUROPE. Available online: https://www.eea.europa.eu/data-and-maps/indicators/main-anthropogenic-air-pollutant-emissions/ assessment-4 (accessed on 8 July 2019).

5. Baleta, J.; Martinjak, M.; Vujanović, M.; Pachler, K.; Wang, J.; Duić, N. Numerical analysis of ammonia homogenization for selective catalytic reduction application. J. Environ. Manag. 2017, 203, 1047-1061. [CrossRef] [PubMed]

6. European Environment Agency. Emissions of the Main Air Pollutions by Sector Group in the EEA-33. Available online: https://www.eea.europa.eu/data-and-maps/daviz/share-of-eea-33-emissions-4 (accessed on 8 July 2019).

7. European Environment Agency. Directive 2010/75/EU on Industrial Emissions (Integrated Pollution Prevention and Control). Available online: https://eur-lex.europa.eu/LexUriServ/LexUriServ.do?uri=OJ:L: 2010:334:0017:0119:en:PDF (accessed on 8 July 2019).

8. Ministry of Ecology and Environment of the People's Republic of China. Annual Statistic Report on Environment in China. 2015. Available online: http://www.mee.gov.cn/gzfw_13107/hjtj/hjtjnb/201702/ P020170223595802837498.pdf (accessed on 8 July 2019).

9. Ministry of Ecology and Environment of the People's Republic of China. Report on the State of the Ecology and Environment in China. 2017. Available online: http://english.mee.gov.cn/Resources/Reports (accessed on 8 July 2019).

10. Liu, X.; Tan, H.; Wang, Y.; Yang, F.; Mikulčić, H.; Vujanović, M.; Duić, N. Low NOx combustion and SCR flow field optimization in a low volatile coal fired boiler. J. Environ. Manag. 2018, 220, 30-35. [CrossRef]

11. Shuangchen, M.; Jin, C.; Kunling, J.; Lan, M.; Sijie, Z.; Kai, W. Environmental influence and countermeasures for high humidity flue gas discharging from power plants. Renew. Sustain. Energy Rev. 2017, 73, 225-235. [CrossRef]

12. Dolanc, G.; Strmčnik, S.; Petrovčič, J. NOx selective catalytic reduction control based on simple models. J. Process Control 2001, 11, 35-51. [CrossRef]

13. Forzatti, P. Present status and perspectives in de-NO $\mathrm{NCR}_{x}$ catalysis. Appl. Catal. A 2001, 222, $221-236$. [CrossRef]

14. Cheng, X.; Bi, X.T. A review of recent advances in selective catalytic $\mathrm{NO}_{x}$ reduction reactor technologies. Particuology 2014, 16, 1-18. [CrossRef]

15. Weber, E.; Schmidt, D. High and Low Dust SCR Processes. In Sulphur Dioxide and Nitrogen Oxides in Industrial Waste Gases: Emission, Legislation and Abatement; van Velzen, D., Ed.; Springer: Dordrecht, The Netherlands, 1991; Volume 3, pp. 223-234.

16. Strege, J.R.; Zygarlicke, C.J.; Folkedahl, B.C.; McCollor, D.P. Bench-scale study of interactions between flue gas and cofired ash in an SCR. Fuel 2006, 85, 2439-2444. [CrossRef]

17. Forzatti, P.; Lietti, L. Catalyst deactivation. Catal. Today 1999, 52, 165-181. [CrossRef]

18. Chen, H.; Luo, M.; Wang, Y.; Zhang, Q.; Liu, Y. Influence of Coal-Fired Boiler Fly Ash on SCR Denitration Catalysts and Preventive Measures. J. Combust. Sci. Technol. 2017, 23, 200-211. (In Chinese)

19. Zheng, Y.; Jensen, A.D.; Johnsson, J.E. Deactivation of $\mathrm{V}_{2} \mathrm{O}_{5}-\mathrm{WO}_{3}-\mathrm{TiO}_{2} \mathrm{SCR}$ catalyst at a biomass-fired combined heat and power plant. Appl. Catal. B 2005, 60, 253-264. [CrossRef]

20. Zheng, Y.; Jensen, A.D.; Johnsson, J.E.; Thøgersen, J.R. Deactivation of $\mathrm{V}_{2} \mathrm{O}_{5}-\mathrm{WO}_{3}-\mathrm{TiO}_{2}$ SCR catalyst at biomass fired power plants: Elucidation of mechanisms by lab- and pilot-scale experiments. Appl. Catal. B 2008, 83, 186-194. [CrossRef]

21. Sadripour, M.; Rahimi, A.; Hatamipour, M.S. Experimental Study and CFD Modeling of Wall Deposition in a Spray Dryer. Dry. Technol. 2012, 30, 574-582. [CrossRef]

22. Hossain, A.; Naser, J.; Imteaz, M.A. CFD Investigation of Particle Deposition in a Horizontal Looped Turbulent Pipe Flow. Environ. Model. Assess. 2011, 16, 359-367. [CrossRef]

23. Zhang, J.; Li, A. CFD simulation of particle deposition in a horizontal turbulent duct flow. Chem. Eng. Res. Des. 2008, 86, 95-106. [CrossRef]

24. Xu, Y.; Zhang, Y.; Liu, F.; Shi, W.; Yuan, J. CFD analysis on the catalyst layer breakage failure of an SCR-DeNO $x$ system for a 350MW coal-fired power plant. Comput. Chem. Eng. 2014, 69, 119-127. [CrossRef] 
25. Yu, C.; Si, F.; Ren, S.; Jiang, X. Experimental and numerical predictions of ash particle erosion in SCR monolithic catalysts for coal-fired utility boilers. Korean J. Chem. Eng. 2017, 34, 1563-1575. [CrossRef]

26. Feng, H.; Wang, C.; Huang, Y. Particle deposition behaviors of monolithic $\mathrm{DeNO}_{x}$ catalysts for selective catalytic reduction (SCR). Korean J. Chem. Eng. 2017, 34, 2832-2839. [CrossRef]

27. Heiredal, M.L.; Jensen, A.D.; Thøgersen, J.R.; Frandsen, F.J.; Friemann, J. Pilot-Scale Investigation and CFD Modeling of Particle Deposition in Low-Dust Monolithic SCR DeNOx Catalysts. AIChE J. 2014, 69, 119-127. [CrossRef]

28. ANSYS Inc. ANSYS Fluent User's Guide, Version 17.1; ANSYS Inc.: Canonsburg, PA, USA, 2016.

29. Kuang, M.; Li, Z.; Zhu, Q.; Chen, L.; Zhang, Y.; Lai, J. Gas/Particle Flow Characteristics, Combustion and $\mathrm{NO}_{x}$ Emissions of Down-Fired 600MW $\mathrm{MW}_{\mathrm{e}}$ upercritical Utility Boilers with Respect to Two Configurations of Combustion Systems. Energy Fuels 2012, 26, 3316-3328. [CrossRef]

C 2019 by the authors. Licensee MDPI, Basel, Switzerland. This article is an open access article distributed under the terms and conditions of the Creative Commons Attribution (CC BY) license (http://creativecommons.org/licenses/by/4.0/). 